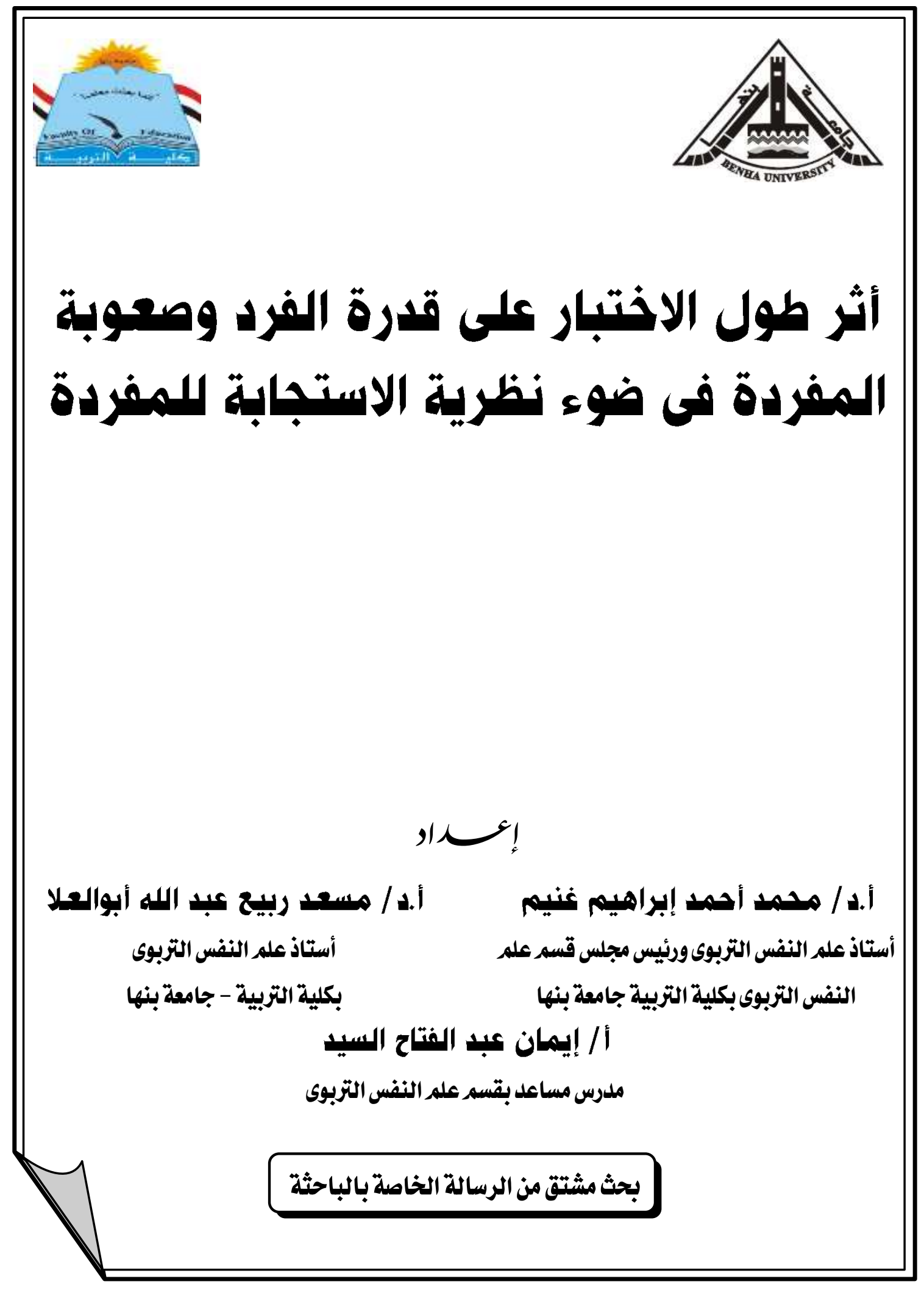




\section{أثر طول الاختبار على قدرة الفرد وصعوبة المفردة فى ضوء نظرية الاستجابة للمفردة}

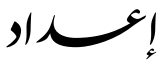

\section{أ.د/ مسعد ربيع عبد الله أبوالعـلا \\ أستاذ علم النفس التربوى

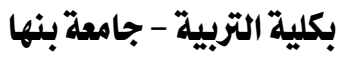 \\ أ.ده/ محمد أحمد إبراهيم غنيميم \\ أستاذ عله النفس التربوى ورئيس مجلس قسمر عله \\ النفس التربوى بكلية التربية جامعة بنها}

أ إيمان عبد الفتاح السيد

مدرس مساعل بقسم علم النفس التزبوى

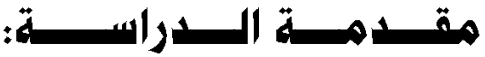

تعد الاختبارات التحصيلية من أهم الأدوات التى تزودنا بالبيانات التى يُستتد إليها فى اتخاذ العديد من القرارات التربوية التى تخص الفرد والمجتمع، حيث تُصمم لأهداف متتوعه منها اختيار شخص لوظيفة ما أولأغراض التصنيف لتحديد مسار الطلاب بما يتاسب مع قدراتهم ومهاراتهم من لنابن

خلال تقويم تحصيل الطلاب فى ضوء الدرجات التى يحصلون عليها فى الاختبارات الصفية. كما يعد التطور الذى حدث فى الاختبارات والعملية الاختبارية أساساً لتحسين العملية

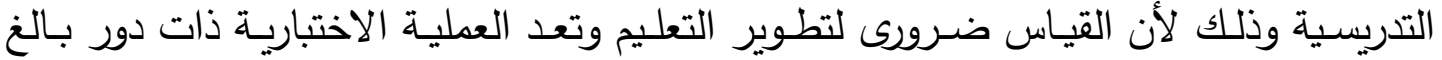
الأهمية للعمل التربوى والعملية التدريسة بخاصة وليست منفصلة عن أى منهما فعلى المعلم أن يدرك أن أهداف العملية الأختبارية يجب أن تتطابق مع أهداف العملية التدريسية مما يتطلب التعال تطوير أساليب اختبارية متتوعة بدرجة كبيرة وكل من هذه الأساليب يكون له إسهاماته المتفردة

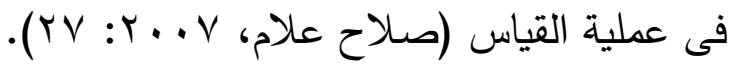
والجدير بالذكر أن الاختبارات التحصيلية التى يُعتنى ببنائها يمكن أن تستثير دافعية الطلاب للتحصيل الجيد وتحقيق الأهداف التعليمية بمختلف مستوياتها وهذا يساعد فى استبقاء

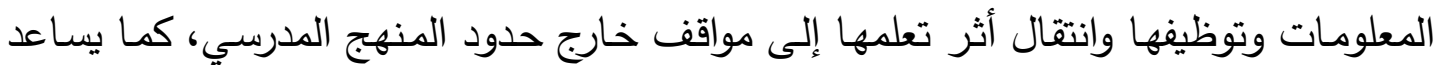
فى تأكيد أهمية التقويم الذاتى الذى يعد مكونه أساسية من مكونات التعلم المستقل للطالب وزيادة دافعيتة وتقديره لذاته وبذلك يعتدد الطالب على الضبط والتحكم غير المباشر والدافعية الداخلية

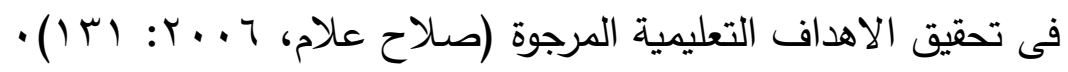
ويذكر (Kesamang, 2017, 3) أن المفردة تخلق نوع من السلوك لدى الممتحن،

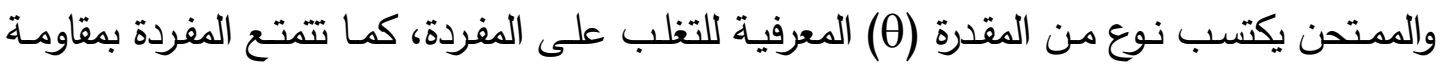
معرفية داخلية (b) لذا فإن إمكانية تغلب الممتحن على المفردة تعتمد على هذين العاملين (b, (b)، 
إذا كانت قدرة الممتحن المعرفية أعلى من الدقاومة المعرفية للدفردة إذاً فإن احتمالية أن يتغلب الممتحن على المفردة تكون أعلى، لذلك نجد أن القياس الجيد يتطلب:

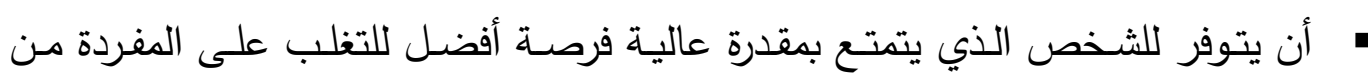
الثخص ذو المقدرة الضعيفة. less أن يتمتع أي شخص بغرصـة أفضل للتغلب على المفردة ذات المستوى الاقل demanding item عن المفردة الأكثر تطلباً.

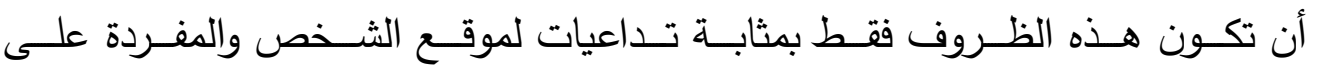

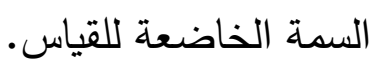

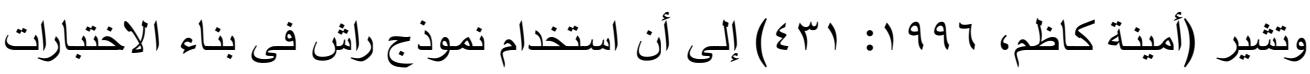
التحصيلية وتكوين بنوك الاسئلة يمكنا من التغلب على مشكلتين من أهم مشكلات التقويم ألتهي

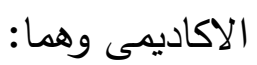

هوضوعية تقدير المستوى الأكاديمى للطالب بالرغم من اختلاف الاختبارات المستخدمة

$$
\text { وتباين مستوياتها. }
$$

موضوعية تقدير المستوى الاكاديمى للطالب بالرغم من اختلاف مستوى الثعبة أو

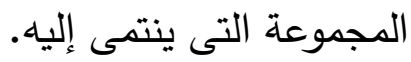
ويُعد الأختلاف الرئيسى بين النمـاذج الكلاسيكية ونمـاذج السمات الكامنهـ فى مجال

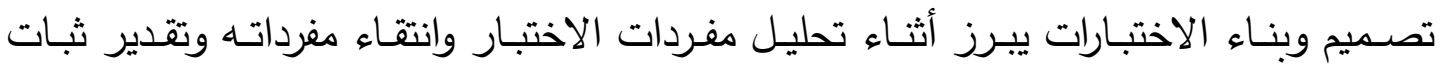
البيانات المستمدة منه والتى تتميز بخاصية عدم التباين Invariance وهوما لا يحدث عند

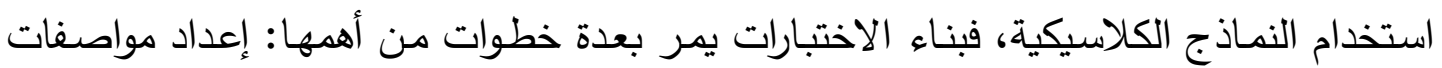
الاختبار ، وكتابـة مفرداته، وتحديـ الخصـائص السيكومترية لهذه الدفردات وانتقاء الدفردات

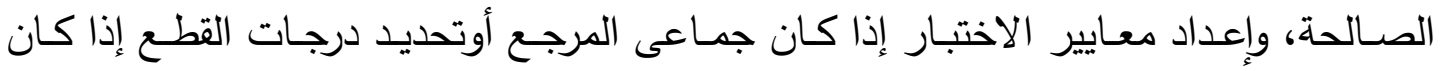

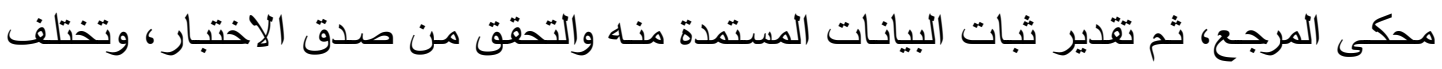

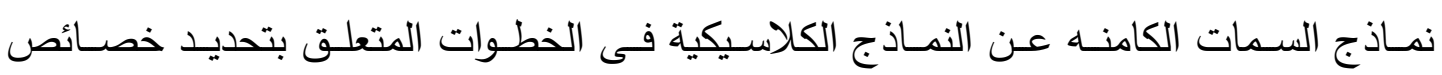

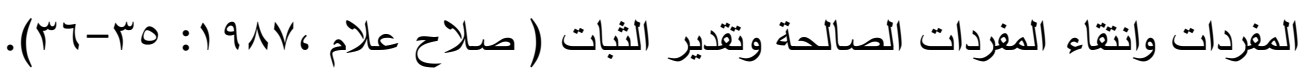

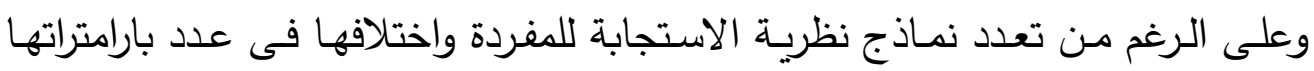

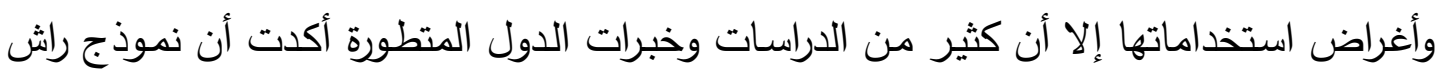

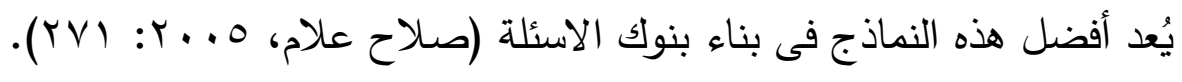




\section{مشكاسلة الــدراسـاسة:}

أُجريت على الاختبارات التحصيليه العديد من الدراسات بهدف التعرف على العوامل

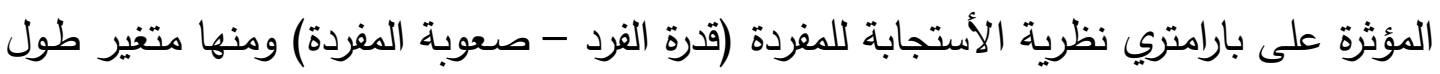
الاختبار ومنها: دراسة (Bastari (2000) التى هدفة إلي بحث أثر طول الاختبار فى مادة اللغة الانجليزية فى مراحل تعليمية متعددة وحجم العينة ونمط المفردة - ثنائية الدرجة "صواب

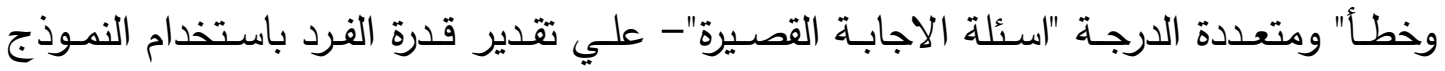
اللوغاريتمى ثلاثى المعلم لمفردات الاختيار من متعدد ومفردات الاستجابة المتدرجه -الاستجابة

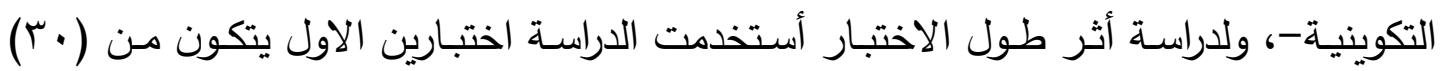
مفردة والثانى يتكون مـن (• (0) مفردة وقد استخدم برنـامج MULTILOG لتقدير معـالم

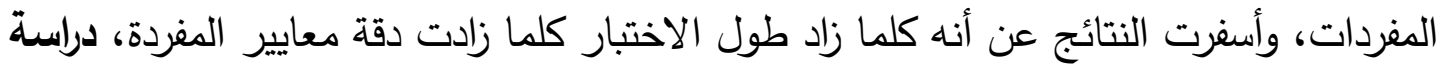

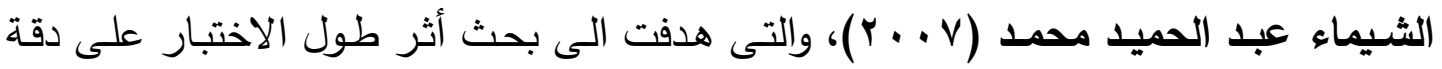

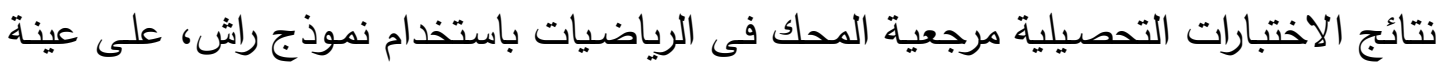

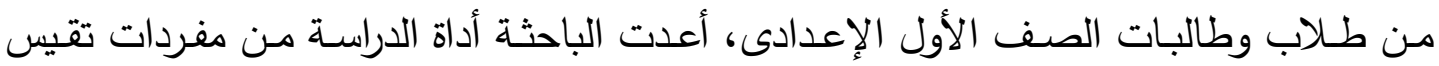

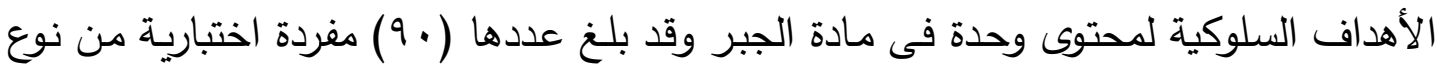

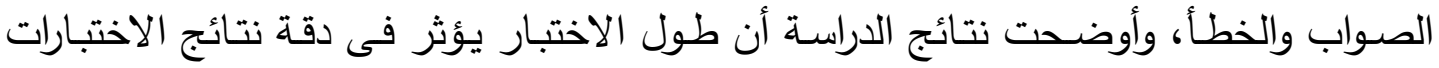

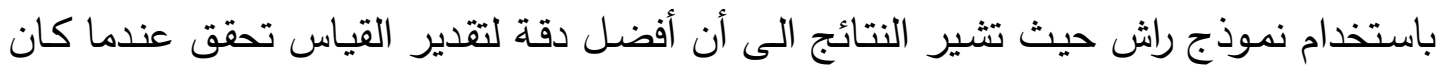

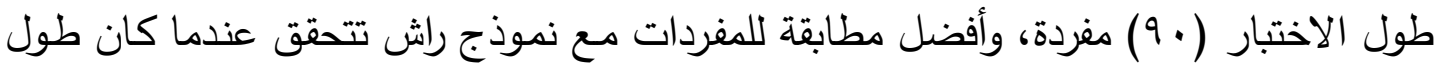

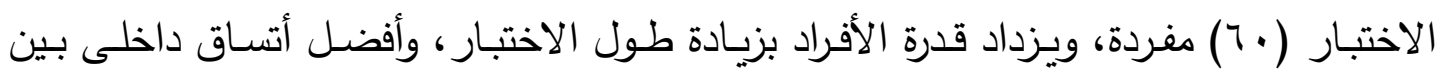

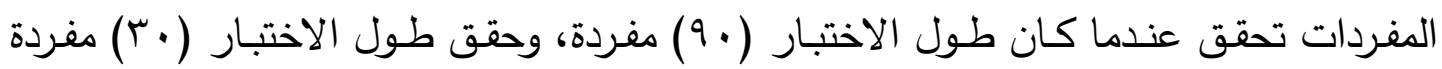

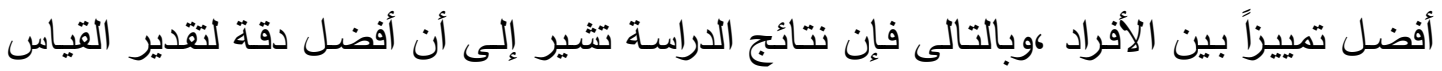

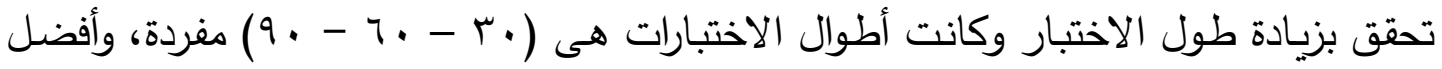

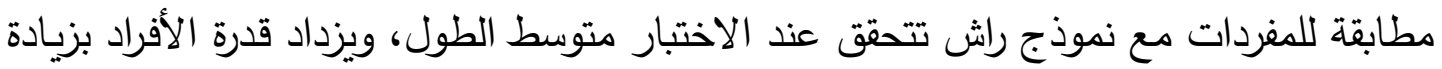
طول الاختبار، وأفضل أتساق داخلى بين المفردات تحقق بزيادة طول الاختبار ، أفضل تمييزاً

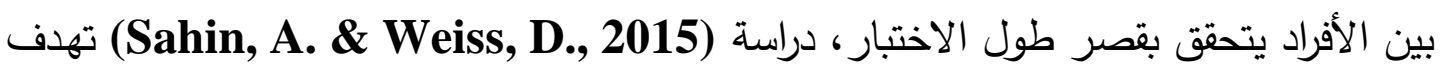

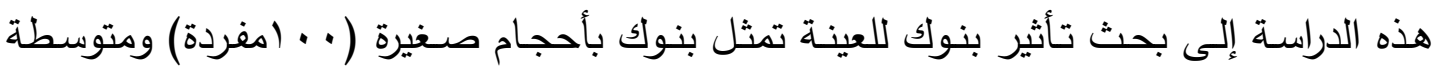

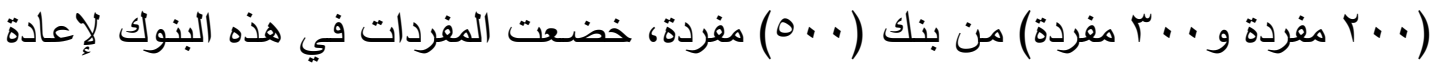


التدريج باستخدام العينات المختارة مع استخدام بارامتراتها المقدرة في الدحاكاة البصرية الخاصة

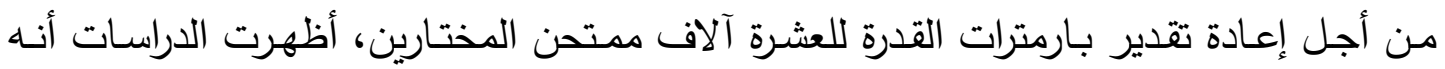

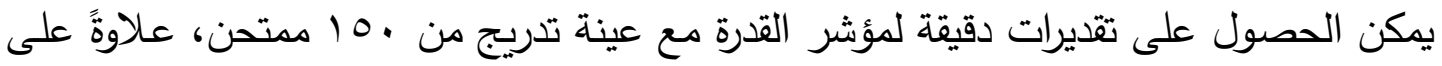

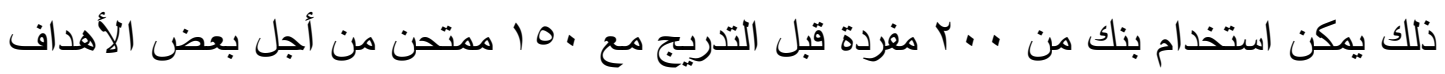

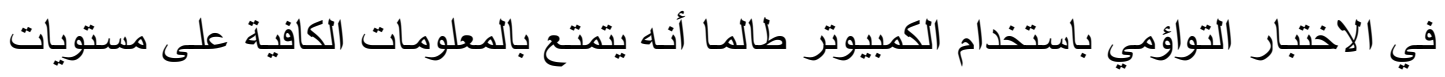
القدرة المستهدفة، تسعى الدراسة للاجابة على التساؤل التالى كيف تتمكن تقديرات القدرة $\theta$ بناءً على تقديرات بارمتر المفردة المستقاة من أحجام متنوعة للعينة والبنك من استعادة تقديرات القدرة

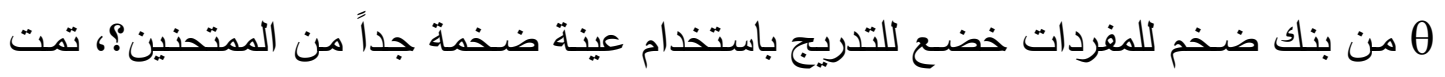
محاكاة مجموعة البيانات الكاملة لهذه الدراسة باستخدام

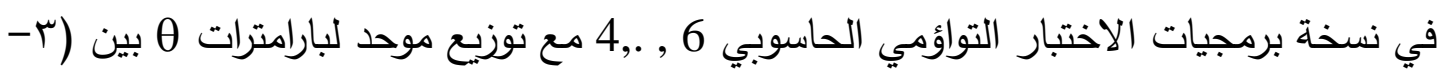

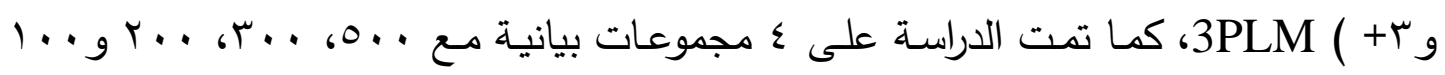

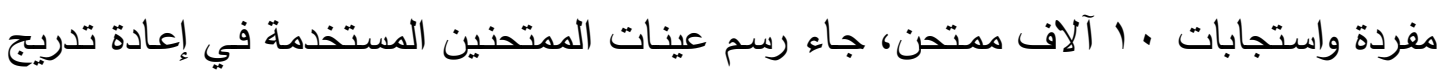

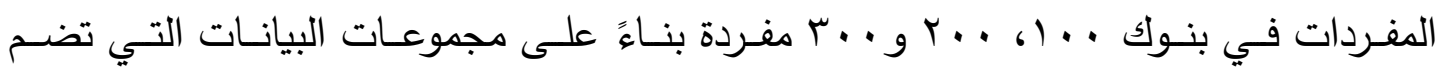
الاستجابات الأصلية (المحاكاة) للمتحنين إزاء المفردات المختارة، كما تم تكوين عينات التدريج

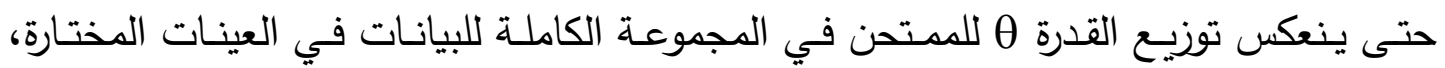

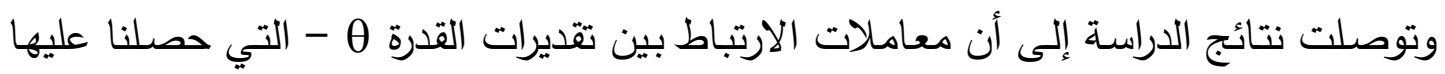

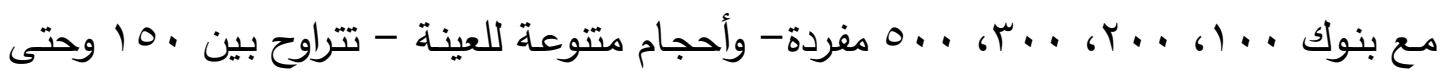

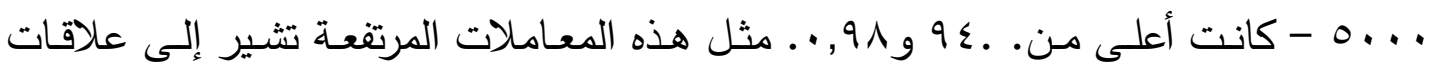
خطية إيجابية قوية بين $\theta$ الحقيقية والتقديرية بغض النظر عن حجم البنك أوعدد الممتحنين،

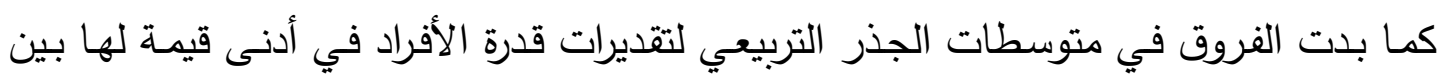

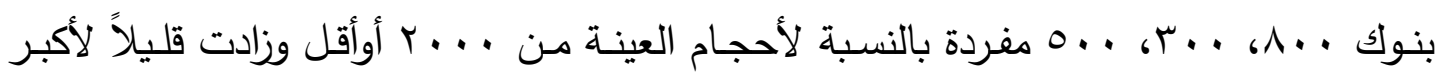

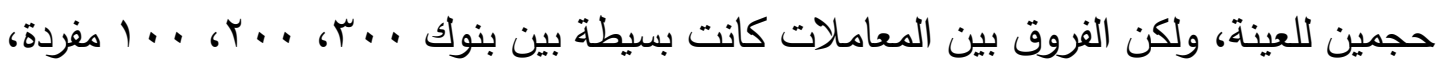

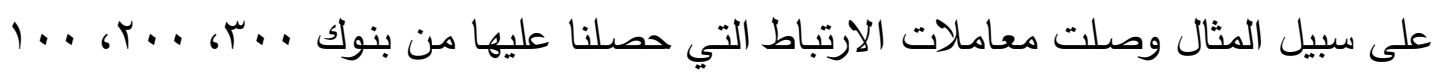

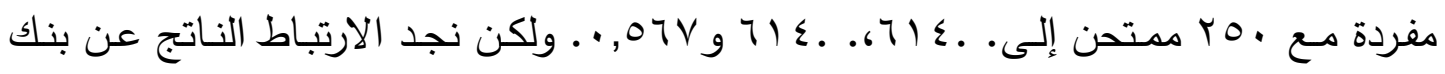

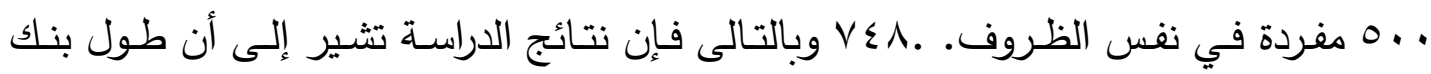

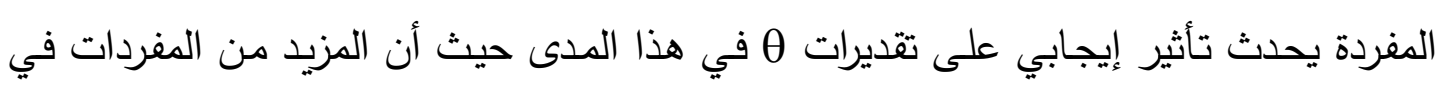

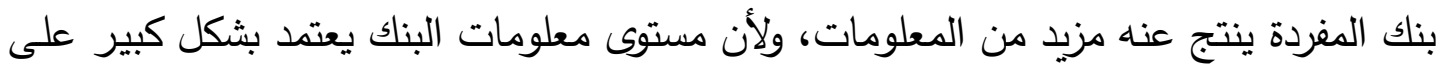


عدد المفردات فيه، نجد أن البنك الذي يضم . . . مفردة أوأكثر قد يعمل بشكل أفضل لخدمة معظم الأهداف المرجوة وقد يقلل من خطر الحصول على تقديرات $\theta$ غير دقيقة في معظم المواقف، عـلاوةً على ذلك في معظم المواقف نجد أن بنك . .. مس مفردة يعمل بنفس كفـاءة بنك . . 0 مفردة قد يعني ذلك أنه عند التخطيط لتطوير بنك مفردة ضخم يجب التفكير في بنك • . . مفردة، تتسق نتائج هذه الدراسة جزئياً مع أدبيات البحث السابقة حيث يوجد عدد محدود من الدراسات المماثلة (بنك من · . . مفردة مدرج على . . . . ممتحن) هوما تم اقتراحه بوصفه ضرورة للحصول على تقديرات $\theta$ دقيقة باستخدام الاختبار التواؤمي في الدراسة الحالية وجدنا أن بنك . . . مفردة يتمتع بجدوى مناسبة لبعض الاهداف، وبالمثل ظهرت جدوى عينة تدريج من • 10 مدتحن للحصـول على تقديرات $\theta$ جيدة في مواقف يتمتع فيها البنك بالمعلومـات الكافية من أجل $\theta$ المستهدفة، دراسة ( Sahin \& Aml (2016، والتى هدفت إلى دراسة أثر طول الاختبار على بارامترات المفردة (الصعوبة، التمييز، التخمين) فى نظرية الاستجابة للمفردة

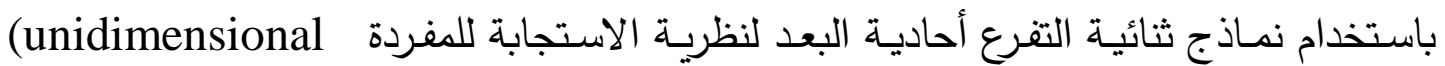
(dichotomous models ) اللغة الإنجليزية في جامعة كبيرة، أما أداة جمع البيانات فهي عبارة عن اختبار لغوي فى الغة إنجليزيـة مكون مـن •ـ مفردة ولتحقيق متطلبـات صسدق المحتوى، يتت تدوين المفردات في الاختبار بشكل متوازي مع أهداف الدورة على يد معلمي اللغة الإنجليزية الذين يدرسون الدورة ويعتبرون خبراء في المادة الدراسية، علاوةً على ذلك قبل تقديم الاختبار تتلقى الجامعة التي تشهد جمع البيانات آراء الخبراء من مرشح لنيل درجة الدكتوراه ومتخصصين في اختبارات اللغة يعملون في مكتب الاختبارات، بهذا تخضع المفردات للمراجعة والتنقيح عدة مرات بناءً على آراء الخبراء حتى الوصول لشكلها النهائي، من ثم يتم تقديم الأداة بشكل متزامن إلى هم عينة الدراسة في جلسة واحدة، استخدمت البيانات المستقاة من هذا الاختبار للحصول على مجموعات بيانية من ثلاث أطوال مختلفة للاختبار ( • (، · ب، • م مفردة)، من ثم يتم استخدام هذه المجموعات البيانية لخلق ظروف بحثية متتوعة حيث يتم التلاعب في طول الاختباروحجم العينة ومتغيرات نموذج نظرية الاستجابة للمفردة وذلك لدراسـة مدى دقة تقدير برامترات المفردة في ظل ظروف مختلفة، أظهرت النتائج المستقاة هنا أنه بجانب حجم العينة أوطول الاختبار يُعد المزيج المكون من هذين المتغيرين هام للغاية ويمكن الاستعانة بالعينات التي تتكون من 


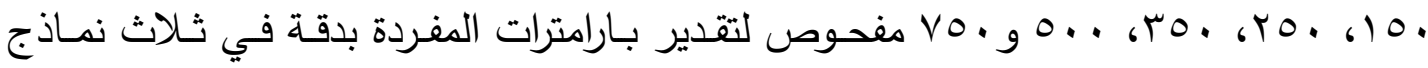

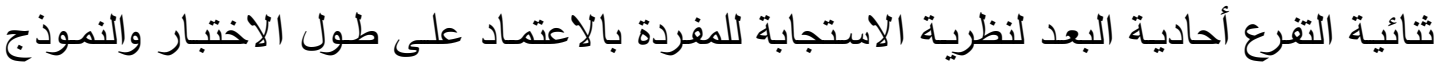

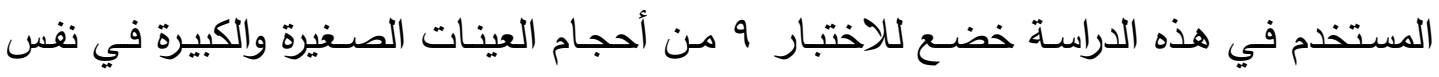

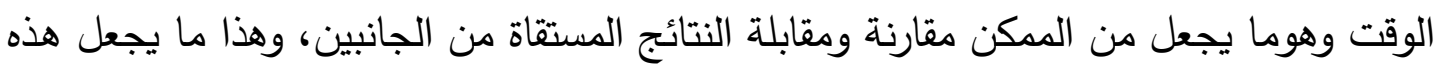

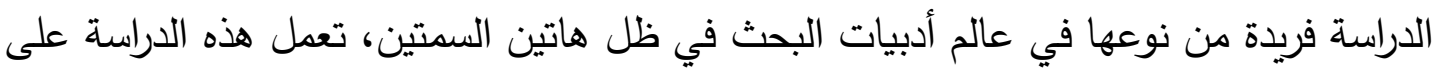

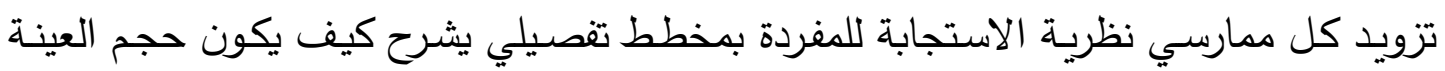

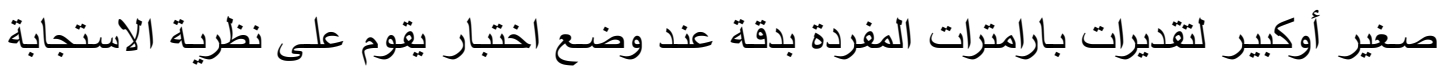

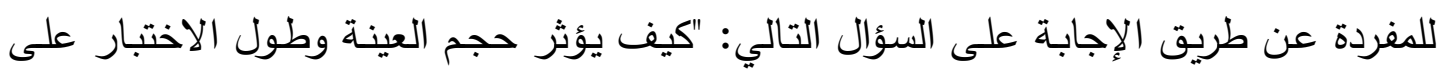

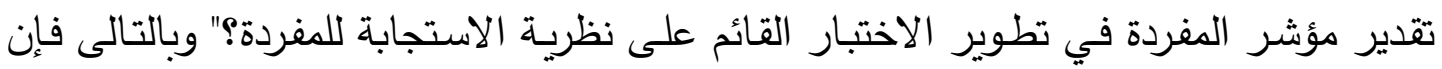

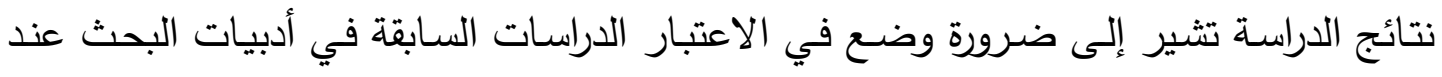
اختيار المفردات للاختبارات القصيرة من المجموعة الكاملة للبيانات لصياغة اختبارات فرعية الصية

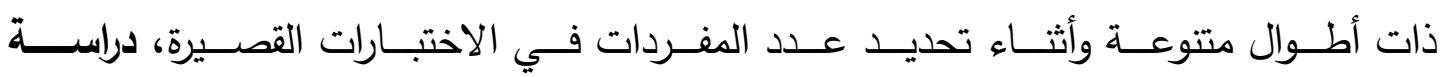

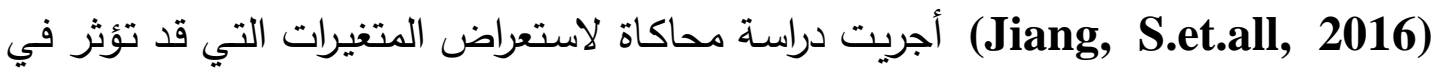
تقدير بارامتر المفردة من أجل نموذج الاستجابة المدرجة متعدد الأبعاد، تم استخلاص البيانات

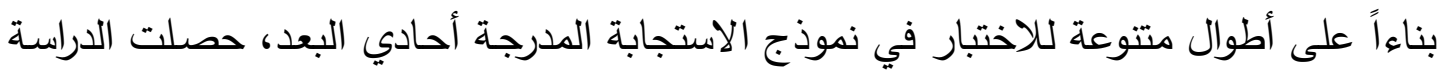

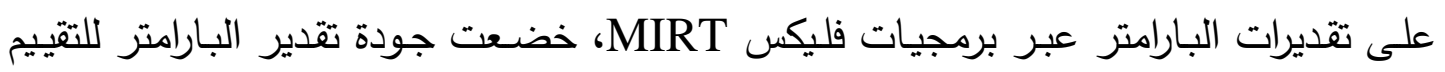

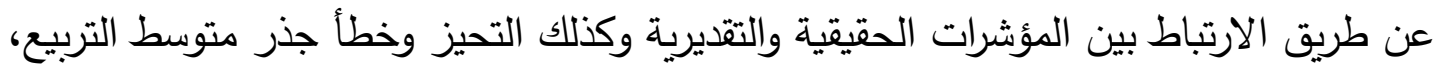

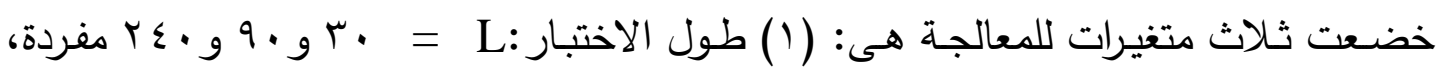

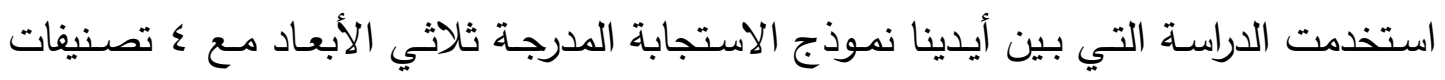

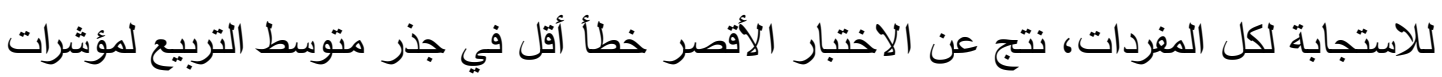

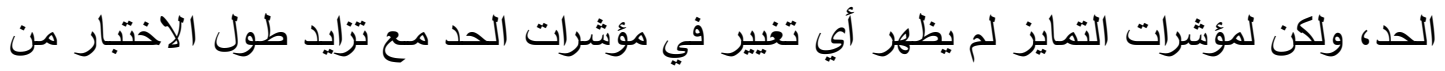

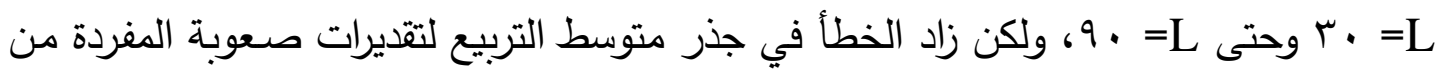
فان

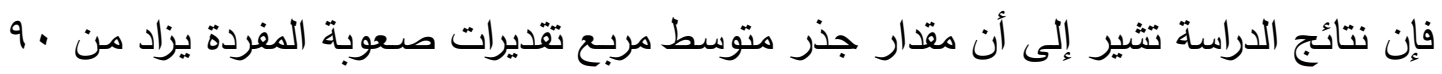

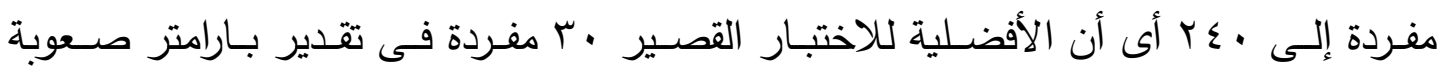
المفردة، دراسـة (Hidalgo, M.et.all, 2016) تهدف إلى مقارنة التراجع اللوجستي المميز واختبارات نسبة الاحتمال لنظرية الاستجابة للمفردة من أجل الدالة المميزة للمفردة في الاختبارات 
(IRT/ RDIF) المتدرجة، من المتغيرات التى تم معالجتها طول الاختبارجيث تتألف الاختبارات المحاكاة من ع ، 0، 1 أو • 1 مفردات المقيـاس الذي يتألف مـن • ا مفردات، توصـلت نتـائج الدراسـة إلى أن معدل الخطأ فى تقدير بارامترات النموذج يتناقص بزيادة طول الاختبار . ويتضح من نتائج الدراسات السابقة: الاختلاف بين نتائج الدرسات والأبحاث حول أفضلية أطوال الاختبارات المستخدمة فى لـي التحليل، حيث أتقتت نتائج دراسة كل من: Bastari(2000)، الثيماء عبد الحميد محمد Hidalgo, et all ‘Jiang, et all(2016) ،Sahin\& Weiss (2015) ، $(r \vee v)$ (2016) على أنـه بزيـادة طول الاختبار يزداد دقة بـارامترات المفردات - صـوبة المفردة

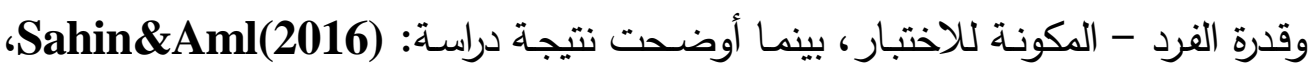
أن الاختبار القصير يعطى تقديرات لصعوبة المفردة أفضل من الأختبارات الأطول. لا يوجد فى حدود علم الباحثة درسات عربية تتاولت أهدافها متغير طول الاختبار على ملى اختبار تحصيلى موضوعى فى مادة العلوم للصف الثانى الأعدادى لبحث أثر متغير طول الاختبار على قدرة الفرد وصعوبة المفردة. وبذلك يمكن تحديد مشكلة الدراسة فى التساؤل التالي: هل تختلف تقديرات معلم صسوبة المفردة ومعلم قدرة الفرد باختلاف طول الاختبار

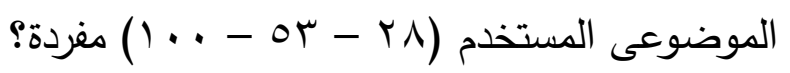

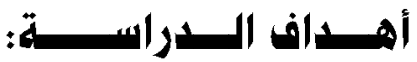

يهدف البحث الحسالى إلى بحث أثر متغير طول الاختبار على قدرة الفرد وصـوبة المفردة وذلك باستخدام نظرية الاستجابة للمفردة.

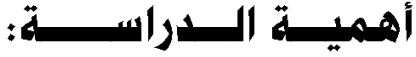

تتمثل أهمية البحث الحالى فى حاجة المؤسسات التربويـة إلى وجود أدوات علمية دقيقه تسـتخدم فى عمليـات التشـخيص والتصـنيف ويُعـد الاختبـار التحصـيلى مـن أكثر الأدوات المستخدمة فى تقييم التحصيل المدرسى الأمر الذى يُسـل القيام بالمهام التعليميه على نحو أكثر فاعليه، ونظرا لأهمية الاختبار التحصيلى تسعى الدراسة الحالية محاولة التعرف على أثر طول الاختبار على بارامترى المفردات المكونه للاختبار التحصيلى؟ 
وبالنظر الى واقع مؤسساتتا التعليمية نلاحظ قلة وندرة استخدام نظرية الاستجابة للمفردة كأسلوب احصائى فى التعامل مع نتائج الاختبارات التحصيلية للاستفادة من فوائدها فى العملية

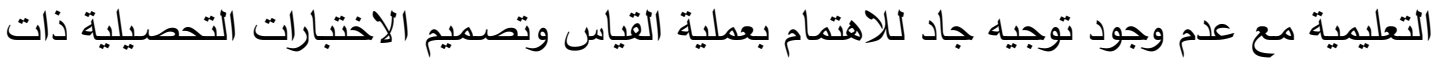

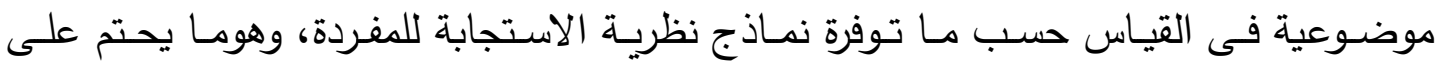
المهتمين بالنواحى التربوية الاهتمام بذلك الجانب الحيوى والهام.

\section{مصطلحسـات الـدراســـة:}

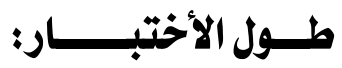

ويقصد به عدد المفردات الخاصسة بكل صورة اختبارية يؤديها الممتحن حيث تختلف

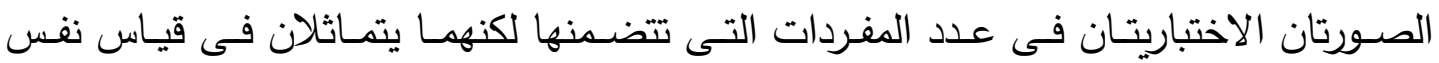
الاهداف السلوكية التى تتضمنها الوحدة الدراسية محل اهتمام الباحثة.

\section{معلـــم صعـــــة المفـــــة}

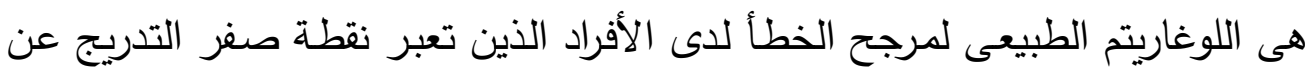

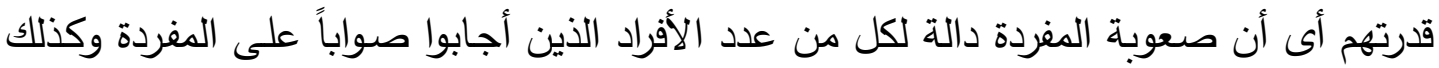

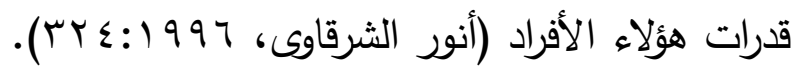

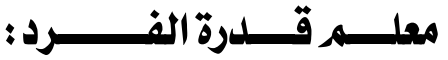

هى اللوغاريتم الطبيعى لمرجح نجاح الفرد على البنود التى تعبر نقطة صفر التدريج عن صعوبتها أى أن قدرة الفرد دالة لكل من عدد المفردات التى أجاب هذا الفرد عليها صواباً

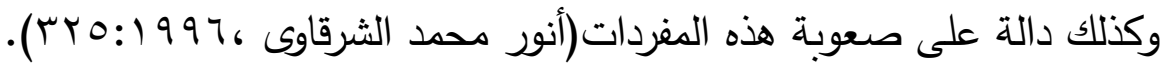

\section{نظـريــة الاستجــــــة للمفــردة:}

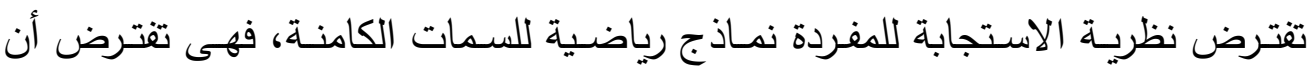

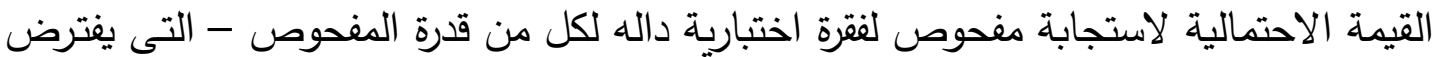
أن الاختبار يقيسها - وخصائص الفقرة التى يحاول الدفحوص الاجابة عنها ومن ثم فإن الدالة المميزه لخصائص المفردة تحدد العلاقة بين مقدار هذا الاحتمال وبين البرامترات المناظرة لقدرة الدفحوص وخصائص الفقرة، ووفق لنماذج هذه النظرية فإن تقديرات قدرة المفحوصين متحررة من تقديرات برامترات المفردات كما أن خصائص الفقرة متحررة من خصائص المفحوصين الذين 
طبقت عليهم ونظرا لأن استجابة المفحوص للمفردة تتضـمن اخطلاء فان هذه النظريـة تهدف للتوصـل لقيم تقديريـة للبـارامترات ومـن ثم استخدام هذه القيم فـى تقدير احتمـال الاسـتجابة الصحيحة لكل مفردة من مفردات الاختبار ، أى أن أداء الممتحن في الاختبار يمكن التتبؤ بـه من خلال مجموعة دن العوامل تسمى السمات والعلاقة بين أداء الممتحن في الاختبار والسمات التي من المفترض أن تؤثر على الأداء، والأداء على الاختبار يمكن وصففه من خـلال دالة متزايدة طردياً تسـى المنحنى المميز للمفردة، ويمثل هذا المنحنى الانحدار غير الخطى للا (درجات التى يحصـل عليها المفحوصـون فى كل مفردة من مفردات الاختبار) على (القيم التقديريـة للسمة أوالقدرة المقاسـة) ومنـهـ يتضـح قدرة المفحوص المنـاظرة لاحتمـال معين لـأداء على فقرة ما، وهناك خمسة افتراضات شائعة لنظرية الاستجابة للمفردة وهم: ( () أحادية البعد، (ץ) الاسـتقلال الموضـعي، (ץ) المنحنيـات المميـزة للمفـردة، (ع) لا تغـاير بـارامترات المفـردة والقدرة، (0) السرعة، (Oji, E. \& Charles, I. , 2016 112:114)، (Akour\&Al) .Omari, 2013, 291;Gleason, 2008, 9 )

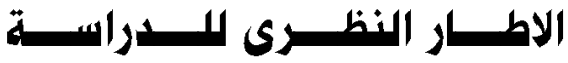

من منطلق مـا تسعى إليـه هذه الدراسـة وهوبحث أثر طول الاختبار التحصيلى على بارامترى المفردة - صعوبة المفردة وقدرة الفرد -، لذا تجدر الإشارة إلى أنه شهد مجال القياس النفسي والتربوي في الآونة الأخيرة اهتماماً ملحوظاً على أيدي خبراء القياس النفسي والتربوي في كثير من دول العالم وذلك لبناء مفردات اختباريـة تساعد على القياس الدقيق لمخرجات التعلم والحصول على تقديرات كمية تتسم بالموضوعية للسمات التي تتطوي عليها استجابات الطلاب لتلك المفردات الاختبارية، وقد تمثل هذا الاهتمام في ثلاثة اتجاهات رئيسة هي: الاتجاه الأول: تمثل في الاهتمـام بالأسس التي يتم في ضـوئها تصـميم وبنـاء المفردات الاختباريـة لقيـاس مخرجات التعلم، وقد سـاعد هذا الاتجاه على ظهور العديد من التقسيمات التربوية التي تفسر التعلم ومخرجاته (Taxonomies ) وتوضـح كيفية بناء المفردات الاختباريـة لقياس مخرجات التعلم المعرفيـة، والوجدانيـة، والمهاريـة. ومـن تلك التقسـيمات التي تهـتم بدراسـة المخرجـات المعرفية للتعلم: تقسيم بلوم( Bloom's Taxonomy) وتقسيم بنية ناتج التعلم الملحوظ ( The Structure of Observed Learning Outcome )، والاتجاه الثاني: تمثل في الاهتمام بالثكل العام للاختبار النفسي والتربوي والعلاقات الداخلية بين المفردات، وقد ساعد هذا الاتجاه 
على ظهور نظريـة الاختبارات العنقوديـة (Testlets) لتوضيح كيفية بناء اختبارات عنقوديـة

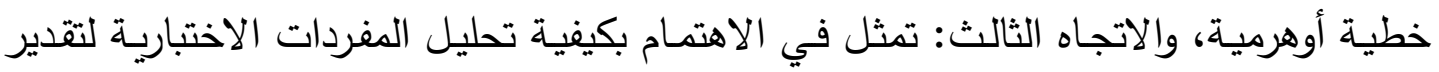

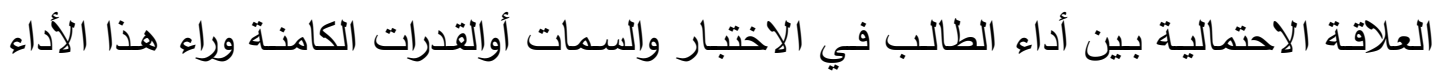
وتفسيرها، وقد ساعد هذا الاتجاه على ظهور نظرية الاستجابة للمفردة ( Item Response ) وما انبثق عنها من نماذج متعددة أكثرها شيوعا نماذج راش (Rheory الاحتمالية، وقد برز هذا الاهتمام في مجال القياس والتقويم كرد فعل للنقد الذي تم توجيهه إلي تقتيم بلوم من ناحية، والنقد الذي تم توجيهه إلي نظرية القياس التقليدية ( Classical Test

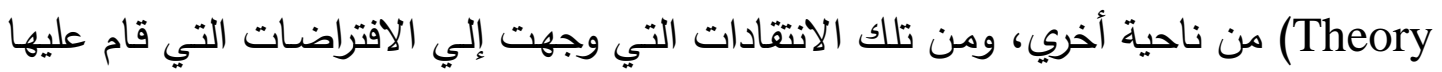
تقسيم بلوم: أنه لا يتم تمثيل المعرفة هرميا، ويصعب الفيه الفصل بين مستوياته الستة، ويوجد تداخل

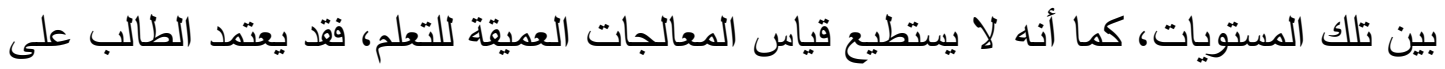

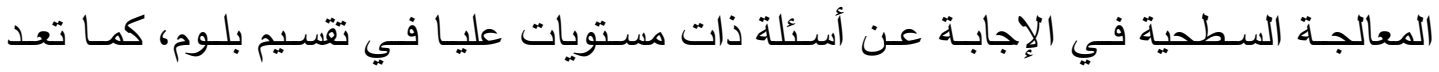
الانتقادات التي وجهت إلي فلسفة القياس النفسي والتزبوي عامة، والنظام المرجعي الجماعـة خاصـة، الأسس التي يستند إليها هذا النظام في بناء الاختبارات والمقاييس النفسية والتربويـة

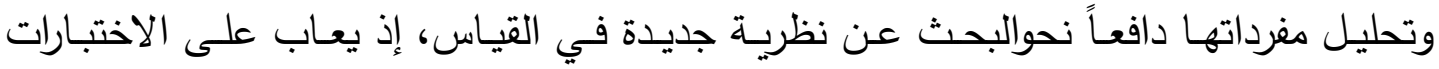

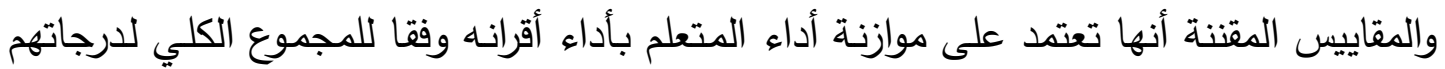
الاختباريه وسواء أجريت هذه الموازنة على أساس الدرجات الخام أوالدرجات المعيارية بأنواعها

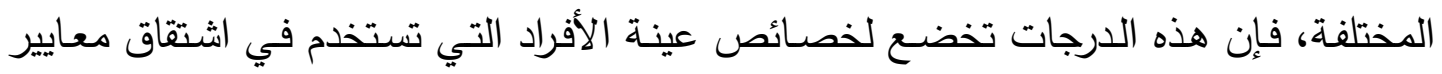

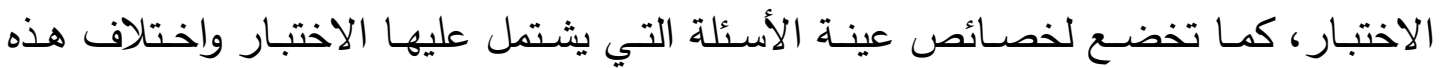

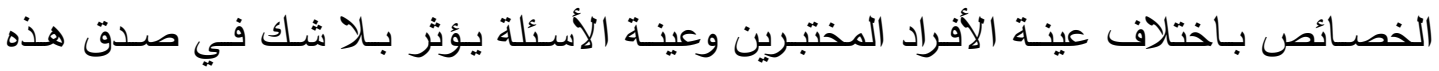

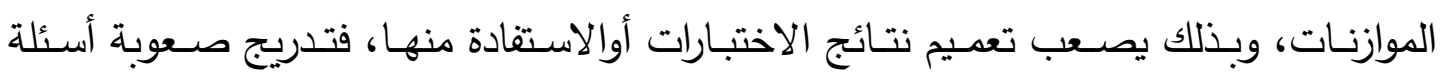

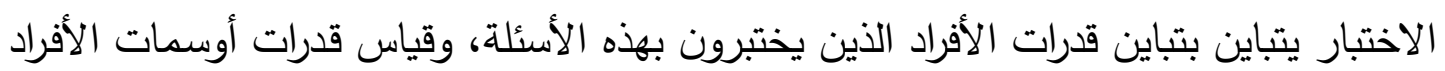

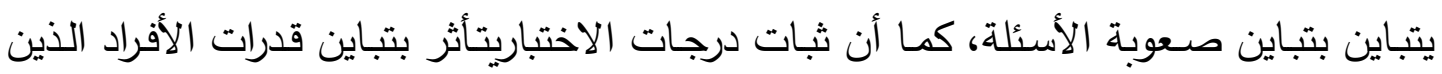

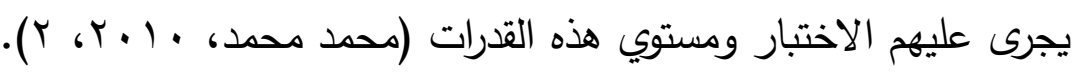

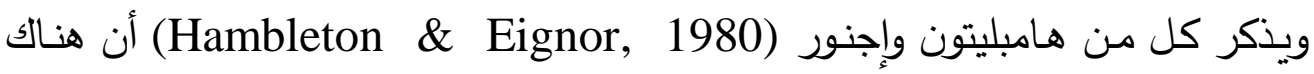
عاملين ينبغى وضعهما فى الاعتبار عند تحديد أسئلة الاختبار وهما: 


\section{1- العلاقة بين عدد أسئلة الاختباروالأهمية الخاصة بكفاية معينة:}

تتفاوت أهمية الكفايات المراد قياسها فى الاختبار لذا ينبغى أن يختار مصدم الاختبار عند قياسه كفايات متعددة أسئلة تتناسب مع أهمية النطاق المراد قياسه.

\section{r- العلاقة بين علد أسئلة الاختبارومستوى الحد الأدنى المقبول للدرجة ثبات الاختبار:} يستدعى ذلك تحديد قيمة الدقة المطلوبة (Degree of Precision) فى تقدير درجة الطالب فى النطاق وذلك يتم وفق الصيغة التالية:

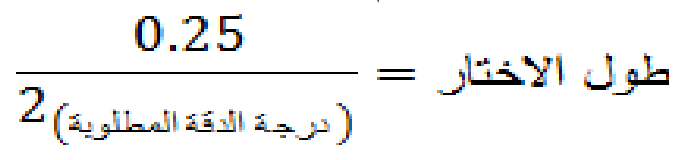

حيث أن (0.25) مقدار ثابت، كما أشار كل من هامبليتون وآخرون Hambleton) et.al., 1978) أن الهلف من تطبيق الاختبار هوتصنيف الطلاب إلى فئتين متقنة وغير متقنة لذا فإن تحديد طول الاختبار المناسب الذى يقلل من أخطـاء التصنيف Classification Errors هالادين ورويد ( Haladen\&Roid) أن قيمة أخطاء التصنيف تقل بشكل عام عند زيادة طول الاختبار لكن النقص فى قيمة الخطأ يكون ملحوظ عند الانتقال من اختبار طوله (• () مفردات

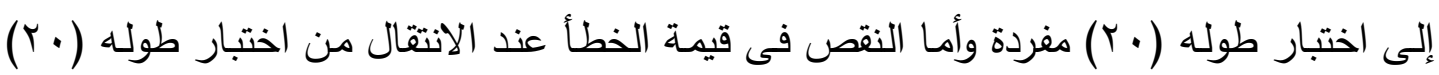

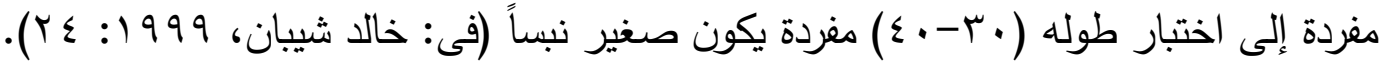

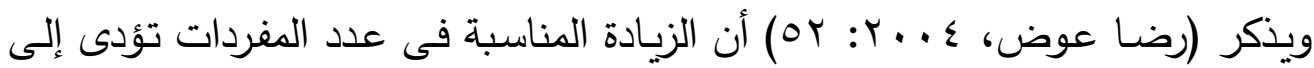

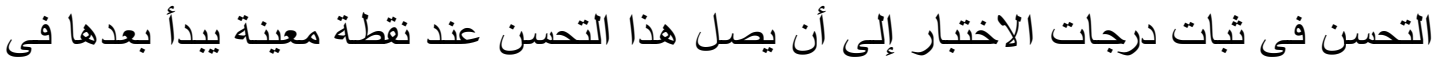
الانخفاض، أى أن الزيادة الاضافية فى عدد المفردات بعد الوصول إلى هذه النقطة لا يقابلها زيادة أوتحسن فى الدرجات نتيجة لانخفاض جهد الطلاب وكذلك الزمن المخصص للإجابة، لذا لذا لإنال

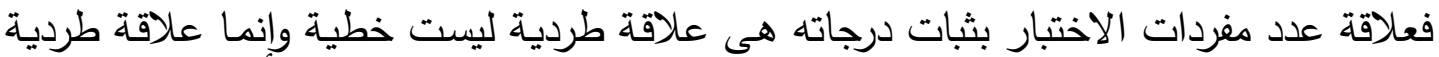
منحنية بمعنى أن الزيادة المناسبة فى عدد المفردات ترفع قيمة معامل ثبات الاختبار عند حد معين ينخفض بعده مع زيادة عدد المفردات. ويشير (Akour \& Al-omari, 2013.292) إلى أن طول أي اختبار وعدد الممتحنين الذي نحتاج إليهم لتقديم تقييم جيد لمعايير المفردة, يكون من الصعب تحديدهم، فالعينات الكبيرة والاختبارات الطويلة نحتاج إليها لتقديم تقييمات دقيقة وخاصـة عندما يتم تقييم كلا من معايير 
الدفردة والقدرة ولهذا السبب توجد معظم تطبيقات IRT في مواقف الاختبار كبيرة المقياس، وعلى

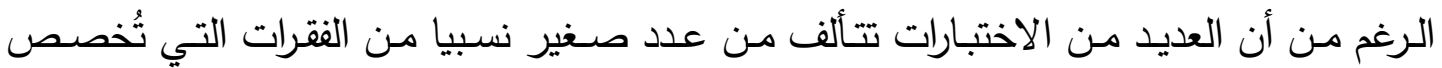
لعينات صغيرة نسبيا من الممتحنين (الاختبارات التي يضعها الدرسين) تم البحث على IRT

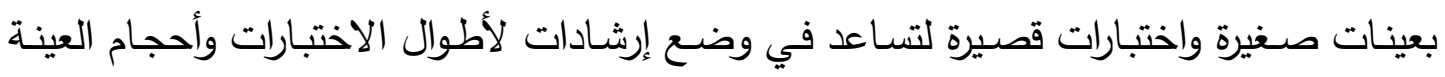

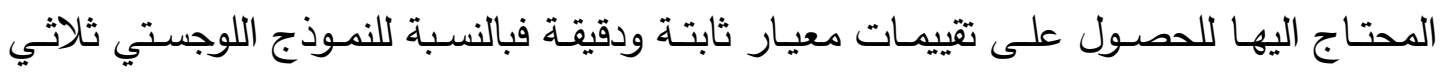

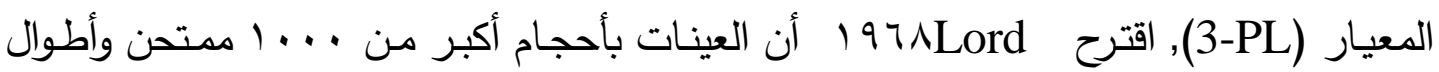

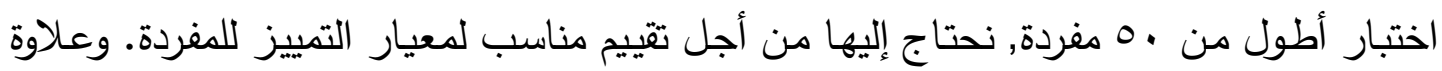

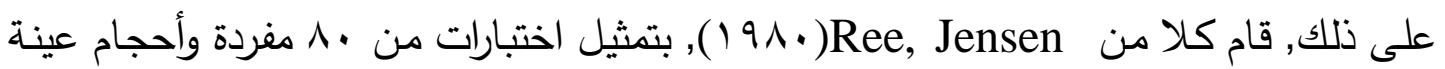

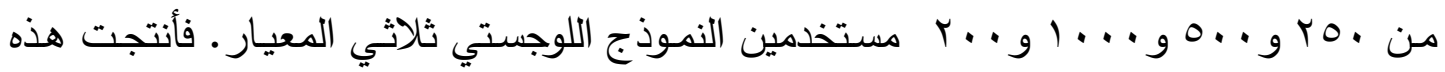

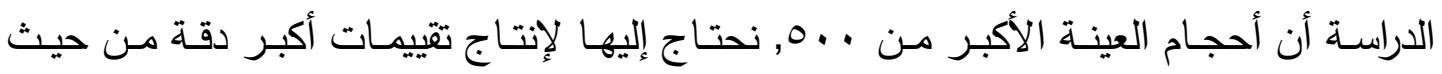

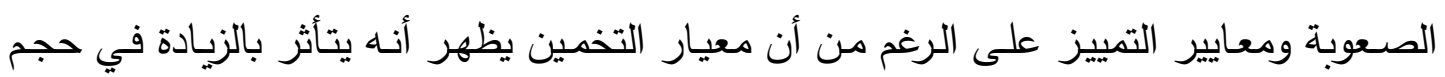

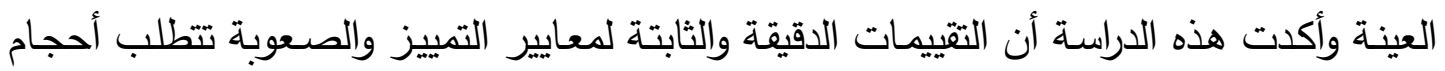

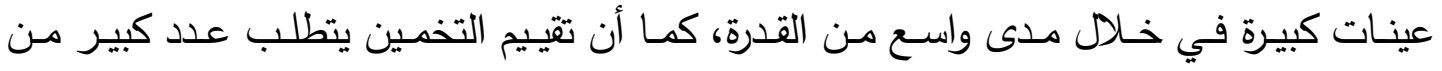
العناصر في المستويات المنخفضة جدا من القدرة، وباستخدام النموذج اللوجستي ثنائي المعيار

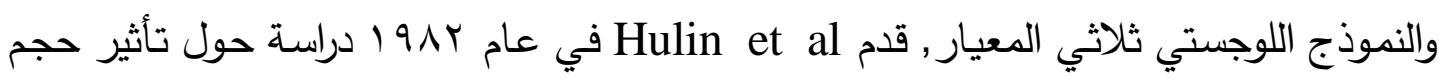

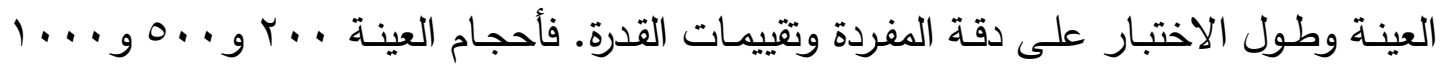

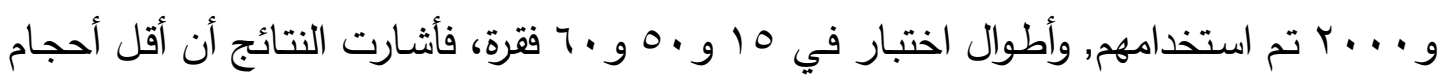
عينـة وأطوال الأختبار تعتمد على استجابة النموذج وأهداف الدراسـة وبالنسبة للنموذج ثـائي

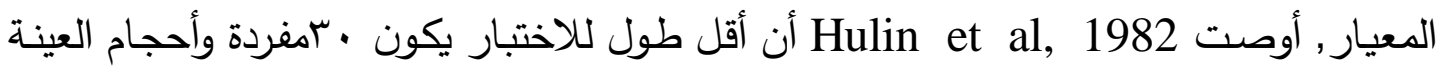

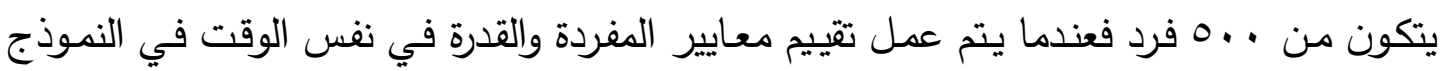

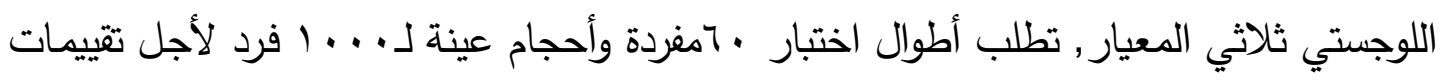

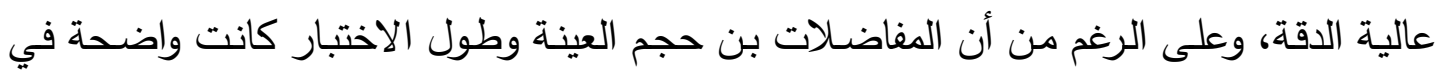

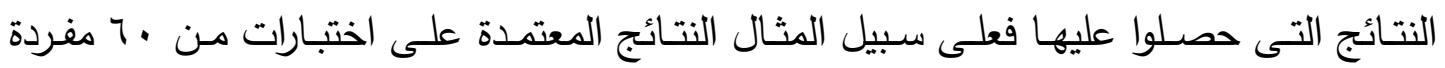

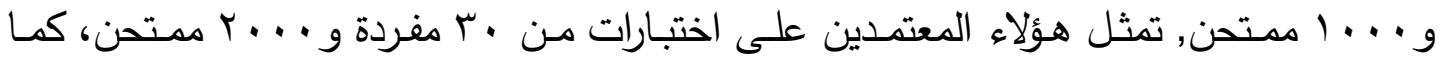

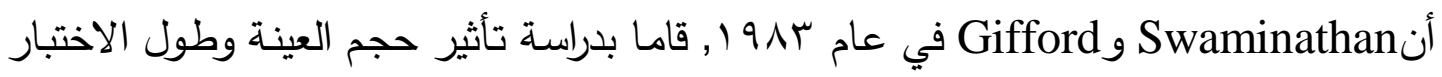


وتوزيـع القدرة على دقـة الفقرة وتقييم القدرة. حيث قـاموا بتمثيـل معلومـات مستخدمين النمـوذج

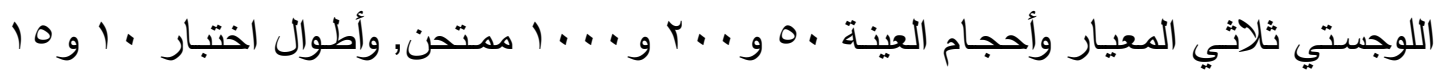
و • rمغردة، فأشارت نتائج هذه الدراسة أن أحجام العينة . . . (ممتحن وطول الاختبار لـ. r مفردة أنتجت تقييمات جيدة جدا للصعوبة ومعايير التخمين وتقييمات جيدة إلى حدا ما لمعيار تمييز الفقرة كما وأثشارت العديد من الدراسات السابقة إلى أن العينة التي تكون أكبر من . . . . ممتحن والاختبار يتكون من مفرد تتطلب تقييمات عالية الدقة لمعايير ثلاثية المفردة, وهذا عندما يكون النموذج اللوجستي ملأُم للمعلومات وعلى الرغم من هذا, لا توجددراسة واحدة من هذه الدراسات تم عملها باستخدام معلومات اختبار حقيقية, بل أنه تم استخدام معلومات افتراضية بدلا من ذلك ويوجد مشكلة في هذا الاتجاه, وهي أنه لا يكون معروفا ما إذا كانت سمات معلومات الاختبار الحقيقي تنعكس في المعلومات الافتراضية، وهذا عندما تكون المعلومات الافتراضية وقيم القدرة مُمثلـة دائمـا مـن توزيـع عـادي بمتوسط صفر وانحراف قياسـي متحد، فنجد أنـه عند استخدام معلومـات حقيقيـة, فإنـه يكون غير مضدون أن توزيعات القدرة سوف تكون طبيعية فإذا كانت توزيعات القدرة منحرفة, فهذا ربما ينتج تقييمات معايير للفقرة أقل دقة, عن التقييمات الحاصل عليها من التوزيعات التي تكون طبيعية وبالتالي فإن المعلومات الحقيقية ربما تُتتج نتائج مختلفة عندما تقارن بالمعلومات التمثيلية فيما يتعلق بدقة معايير الفقرة المقدرة وبالإضـافة إلى هذا فإن استخدام فقط المعلومات التمثيلية ربما يحدد تعميم النتائج على المعلومات الحقيقية.

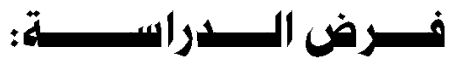

نظراً لتباين نتائج الدراسات والبحوث السابقة فى هذا المجال، فقد صاغت الباحثة فرض

$$
\text { البحث على النحوالتالى : }
$$

تختلف تقـديرات معلـم صـعوبة المفـردة ومعلـم قدرة الفـرد بـاختلاف طـول الاختبـار

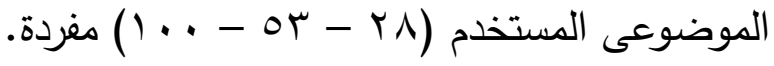

$$
\begin{aligned}
& \text { خطــة وإجـــراءات الــدراســـة }
\end{aligned}
$$

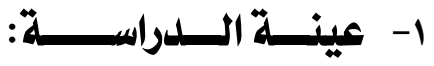

تم اشتقاق عينـة الدراسـة الحاليـة مـن بين تلاميذ الصـف الثانى الأعدادى بمحافظــة

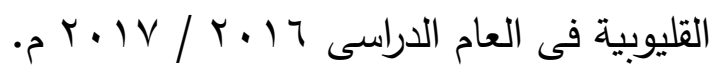




\section{ا-اعينــة الــدراســة الاستطـلاعيـة :}

تكونت عينة الدراسة الاستطلاعية من ( . . () من تلاميذ الصف الثانى الأعدادى بمتوسط

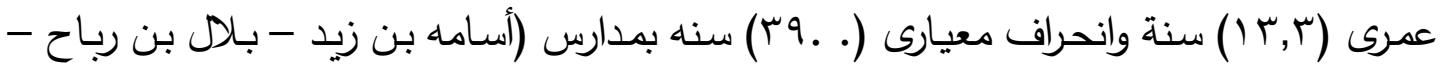

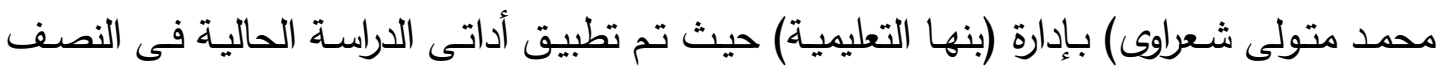

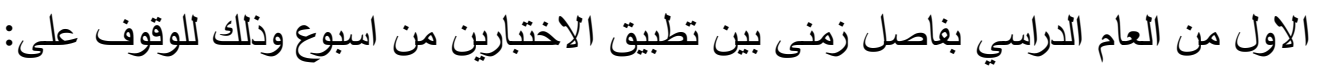

$$
\text { ا ب- مدى وضوح تعليمات الأداة. }
$$

Y- مدى فهم واستيعاب أفراد العينة الاستطلاعية لهفردات الاختبار.

r- الوقوف على الصعوبات التى تواجه الباحثة فى التطبيق المبدئى والعمل على إزالتها

قبل التطبيق النهائى.

$$
\text { ع - الوقوف على الخصائص السيكومترية لأداة الدراسة (ثبات / صدق). }
$$

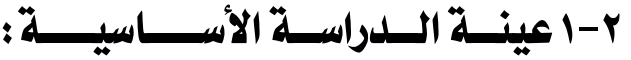

تكونت عينة الدراسة الأساسية الأولية من (7907) تلميذ وتلميذة أختيروا عشوائياً لتطبيق

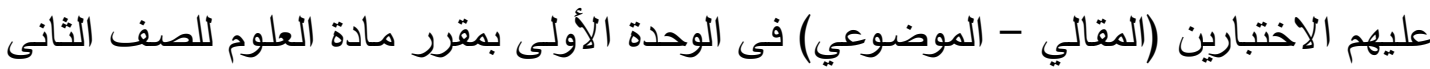

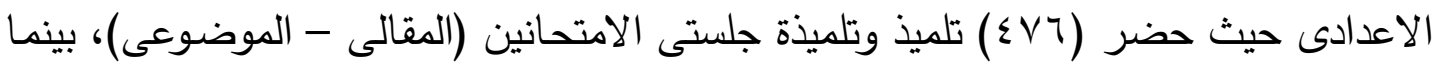

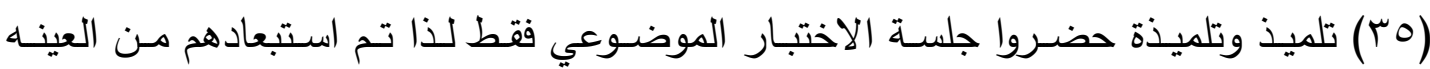
الأساسية و(01) تلميذ وتلميذة حضروا جلسة الاختبار المقالي فقط لذا تم استبعادهم من العينه

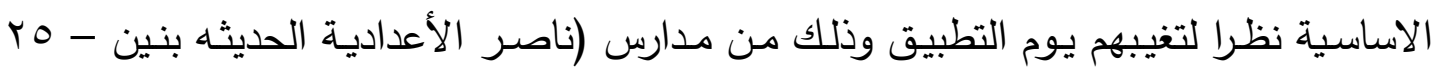
يناير الأعدادية بنات - محمد متولى شعراوى الأعدادية بنين - بلال بن رباح الاعدادية بنين)

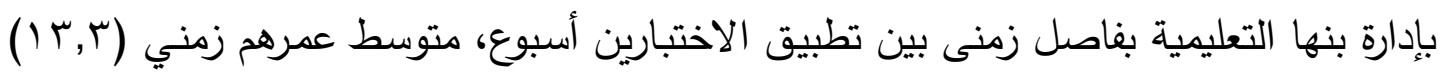

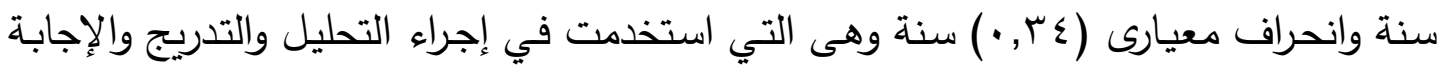
على تساؤلات الدراسة وجدول (1) يوضيح توزيع أفراد العينة.

\begin{tabular}{|c|c|c|c|}
\hline المجموع & إناث & ذكور & الجنس \\
\hline $1 . Y$ & $=$ & $1 . r$ & ناصر الاعدادية بنين \\
\hline 111 & 111 & - & 0 بناير \\
\hline $1 \cdots$ & - & $1 \cdots$ & محمدل متولي شعراوى \\
\hline 107 & $9 V$ & 89 & بلال بنزرباح \\
\hline \&Yๆ & r10 & rq1 & المجموع \\
\hline
\end{tabular}
جدول ( ) توزيع حجم العينة النهائى للتلاميذ الذين أنجزوا جلستى التطبيق 


\section{أم- أداة الـــدراســـــة}

إستخدمت الباحثة فى الدراسـة الحاليـة للإجابـة على فروض الدراسـة اختبـار محكى المرجع فحى مادة العلوم للفصل الاراسى الأول للمرحلة الثانية من التعليم الأعدادى وتم إعداده وفق الإجراءات الأتيـة التى اسـتندت الباحثة فيها على عدة مصـادر فى هذا المجـال وهـى

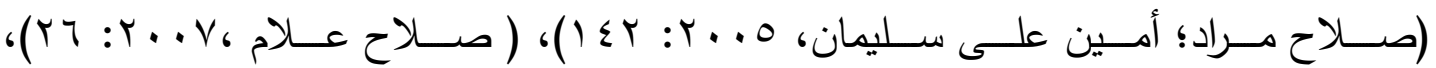
‘(Cunningham, 1986, 154) ‘(Abd.Razak, et.al., 2012, 2205-2207)

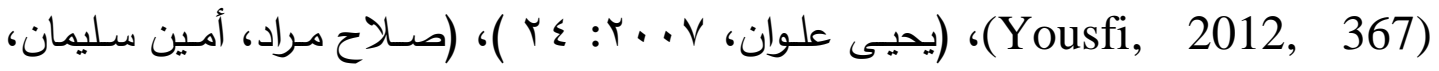

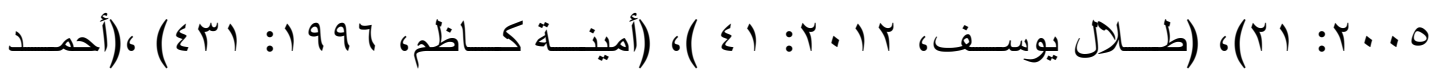

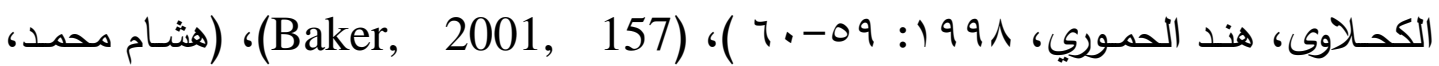

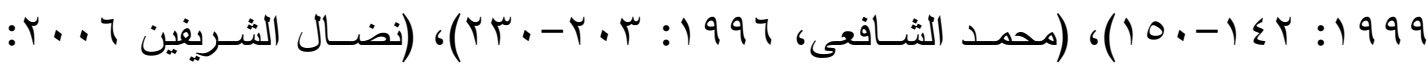

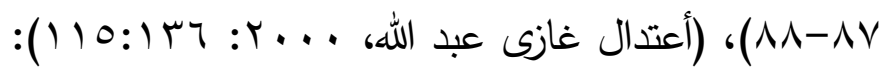
1- تحليل دقيق للوحدة الأولى من فى مقرر الفصل الدراسى الأول من المرحلة الثانية من التعليم الأساسى فى مادة العلوم. r- كتابة الأهداف السلوكية المحددة المنبثقة عن الأهداف العامة. ץ- عرض تحليل محتوى مادة التدريس على المحكمين المختصين وذلك للحكم على مدى توافر البنود التالية: شمولية الاهداف العامة. الاقة فى تحليل المحتوى. الدقة فى تجزئة الاهداف العامة إلى أهداف سلوكية قصيرة المدى. الاقة فى صياغة الأهداف السلوكية. محاولة صياغة اختبار من نمط المفردة ذات الاستجابة الثنائية لقياس كل هدف

$$
\text { من الاهداف السلوكية. }
$$

ع - عقد لقاء ات مـع المحكمين ومناقشتهم فى ملاحظتهم واستجاباتهم على البنود السـابقة التى أعتمدوا عليها فى الحكم على صلاحية مفردات الاختبار. 0- إجراءات التعديلات التى تم الاتفاق عليها مع المحكمين. 
1- تدريج الاختبار باستخدام برامج الحاسوب الخاصـة بنموذج راش الذى ينتمى لنظريـة

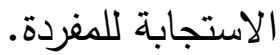

\section{وصف الاختبارالتحصيلى فى صورته الاولية :}

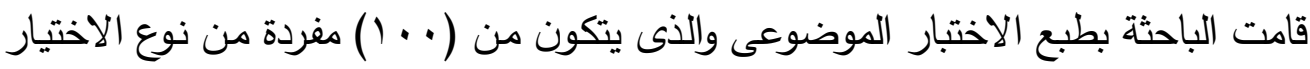
من متعدد للتطبيق المبدئ بهذف التأكد من صلاحيته للتطبيق النهائى وتحديد زمن الاجابه الملائم.

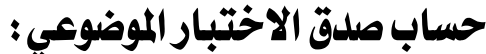

الخصائص السيكومترية لحساب صدق الاختبار :

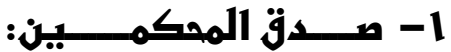

تم تقدير صدق المحكمين للوقوف على صدق الاختبار؛ وذلك بعرض الاختبار على

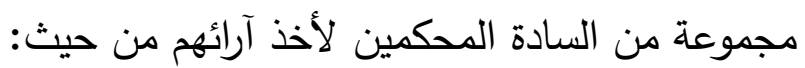

1- كفاية التعليمات المقدمة للتلاميذ للإجابة بطريقة صحيحة على الإختبار.

ه أسفر ذلك عن وضوح التعليمات بالأتفاق مع أراء المحكمين.

r- بلاحية المفردات علمياً، ولغوياً.

أسفر ذلك عن إضـافة للسؤال الاول ليكون صحيح علمياً ولذلك تم تعديله من

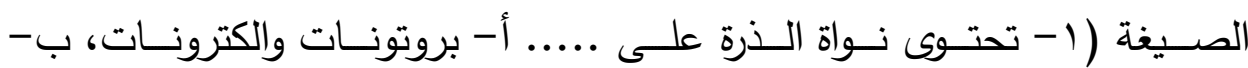

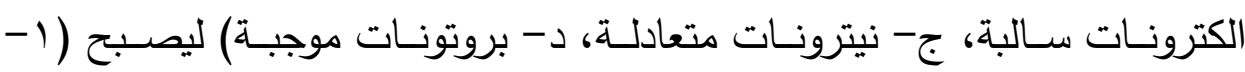
تحتوى نواة الذرة على ..... أ- بروتونات ونيترونات، ب- الكترونات سالبة فقط،

ج- نيترونات متعادلة فقط، د- بروتونات موجبة فقط). وتم تعديل السؤال الثانى من الصيغة ( تدور الأكترونات حول نواة ذرة العنصر فى لئه

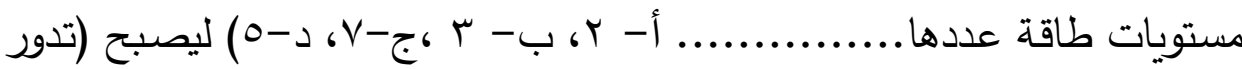
الألكترونات حول نواة ذرة الصوديوم فى مستويات طاقة عددها............... أ-

$$
\text { اثنان، ب- ثلاثه، جسبعة، د-خمسة). }
$$

كما تم تعديل السؤال الثامن من (أثناء التفاعل الكيميائى تثقد ذرة البوتاسيوم الكترون

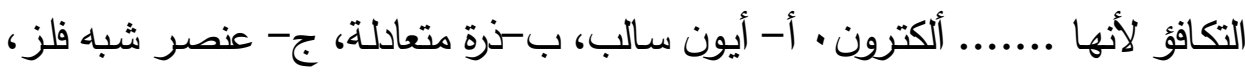
د- أيون موجب) إلى (أثناء التفاعل الكيميائى تفقد ذرة البوتاسيوم الكترون التكافؤ متحوله إلي ....... أ- أيون سالب، بــنزة متعادلة، ج- عنصر شبه فلز ، د- أيون موجب). 
وتعديل السؤال الثانى عشر من ( يستخدم لحفظ قرنية العين . . . . .أ-النيتروجين

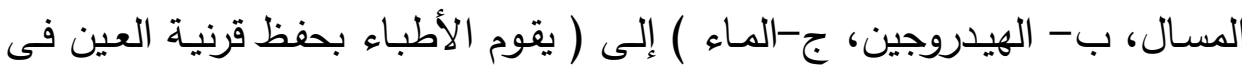

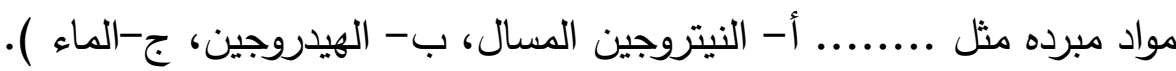
وأيضاً السؤال الحادى والعشرين من ( يتجمد الماء عند درجة....... درجة مئويه.

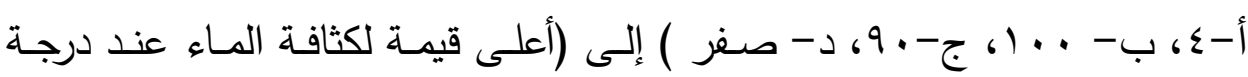

$$
\begin{aligned}
& \text { نأية } \\
& \text { r- مناسبة المفردات لتلاميذ الصف الثانى الإعدادى. }
\end{aligned}
$$

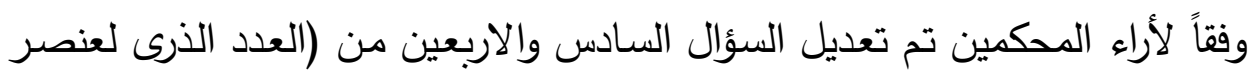

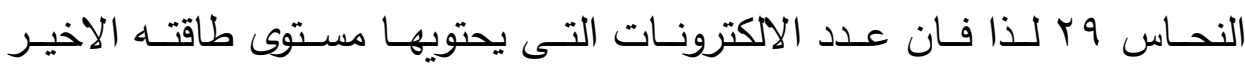

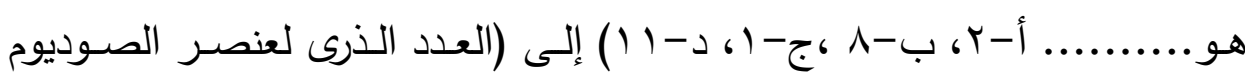

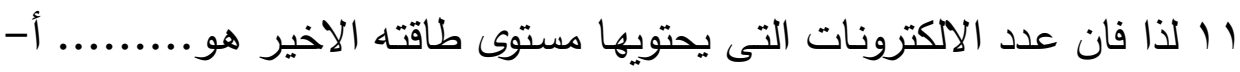

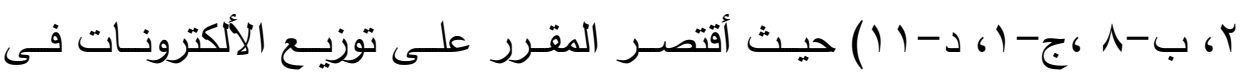

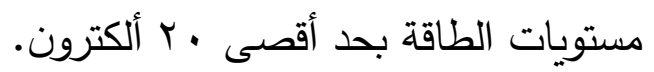
ع - مناسبة كل سؤال للمستوى الذى وضع لقياسه.

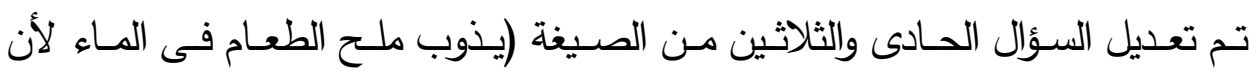

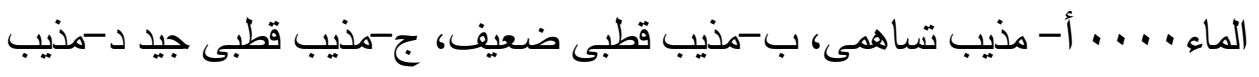
أيونى) • إلى (يذوب2 قطبى ضعيف، ج-مذيب قطبى جيد د-مذيب أيونى) ليتاسب مع مستوى التطبيق.

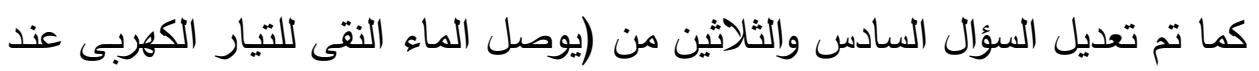

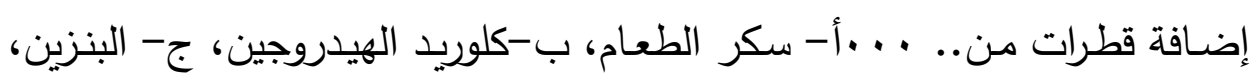
د- حمض الكبرتيك ) إلى (عند تحليل النقى أ- سكر الطعام، ب-كلوريد الهيدروجين، ج- البنزين، د- حمض الكيل الكبرتيك )

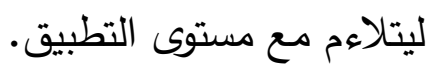

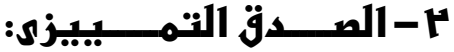

للتحقق مـن القدرة التمييزيـة للاختبـار ؛ تم حسـاب الصدق التمييزى على عينـة الدراسـة الاستطلاعية البالغ عددها ( . . (1) تلميذ وتلميذة؛ بحساب معامل التمييز لكل مفردة من مفردات 
الاختبار بعد ترتيب درجات التلاميذ تنازلياً حسب درجاتهم فى الاختبار ، وفصل Vr\% من درجات

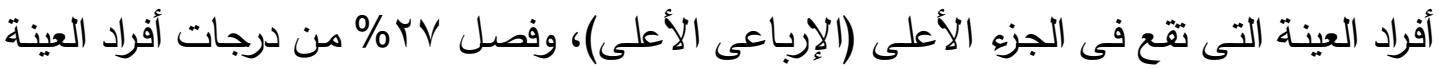
التى تقع فى الجزء الأسفل (الإرباعى الأدنى) ثم استخدام معادلة جونسون لحساب معامل الإنل التمييز ،

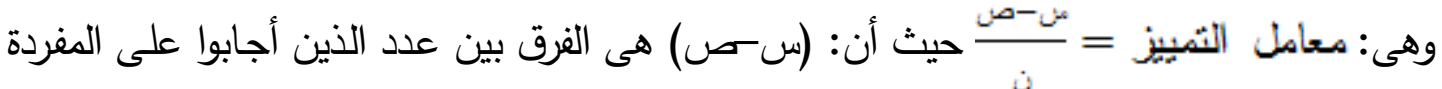

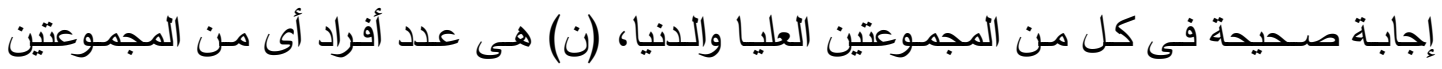

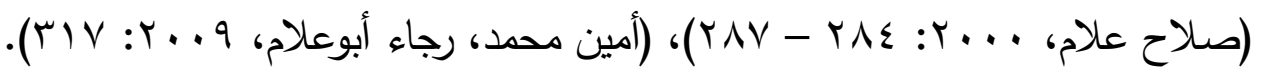
ويعتبر معامل التمييز للمفردة مفبول إذا زاد عن (؟, •)، ولذلك فإن الاختبار التحصيلي

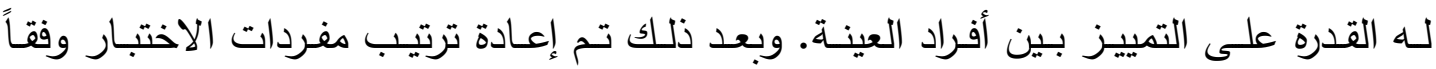
لمعاملات الصـوبة لكل مفردة وجدول (r) يوضح قيم معاملات التمييز لهفردات الاختبار

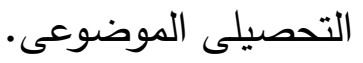

جلول (r) معاملات التمييز لمفردات الاختبار التحصيلى الموضوعي المجوعتى الطلاب العليا والدنيا

\begin{tabular}{|c|c|c|c|c|c|c|c|}
\hline$\frac{D-U}{27}$ & D & $\mathbf{U}$ & ID & $\frac{D-U}{27}$ & D & $\mathbf{U}$ & ID \\
\hline$\cdot, \mathrm{VA}$ & $r$ & rr & 01 & $\cdot, \wedge 0$ & $\xi$ & $r V$ & 1 \\
\hline •,Al & $\xi$ & rq & or & $\cdot, \mathrm{V} \varepsilon$ & $\xi$ & $r \xi$ & $r$ \\
\hline$\cdot, 10$ & $r$ & ro & or & $\cdot, \sum \wedge$ & Ir & rq & $r$ \\
\hline$\cdot, r$. & $r$ & $r r$ & $0\}$ & •, Or & ir & rq & $\boldsymbol{\xi}$ \\
\hline -,07 & 7 & $r$ & $\Delta 0$ & $\cdot 07$ & 9 & $r \varepsilon$ & 0 \\
\hline •, IV & $v$ & ro & 07 & זד, • & 1. & YV & 7 \\
\hline$\bullet, v$. & $\xi$ & $r r$ & or & זד, • & 1. & $r V$ & $v$ \\
\hline$\cdot, \mathrm{VA}$ & 0 & rq & $\Delta \Lambda$ & •, TV & $r$ & rI & $\Lambda$ \\
\hline$\cdot, r$. & $\xi$ & $r r$ & $\Delta q$ & - Or & $\Lambda$ & $r Y$ & 9 \\
\hline •, & $r$ & $r V$ & 7. & ז & $\Lambda$ & ro & 1. \\
\hline ז" , • & 7 & $r r$ & 71 & $\cdot, 07$ & $\Lambda$ & r & 11 \\
\hline$\cdot, \mathrm{r}$ & 1 & r. & Tr & •, IV & $\xi$ & $r r$ & ir \\
\hline$\cdot, \vee \wedge$ & 7 & rV & r & • & $1 \varepsilon$ & Yq & Ir \\
\hline$\cdot, \wedge 9$ & $r$ & Tr & $7 \xi$ & $\cdot, \mathrm{VA}$ & $r$ & זr & $1 \xi$ \\
\hline$\cdot, 07$ & 11 & rq & 70 & $\cdot, 19$ & $r$ & rq & 10 \\
\hline זד, • & 7 & $r r$ & 77 & $\cdot, \mathrm{A}$ & $r$ & $r \varepsilon$ & 17 \\
\hline •, & $r$ & rV & TV & $\bullet, v \cdot$ & 0 & $r \xi$ & iv \\
\hline$\cdot,\{\wedge$ & Ir & rq & 71 & •,Or & Ir & YV & 11 \\
\hline
\end{tabular}




\begin{tabular}{|c|c|c|c|c|c|c|c|}
\hline$\frac{D-U}{27}$ & D & $\mathbf{u}$ & ID & $\frac{D-U}{27}$ & D & $\mathbf{U}$ & ID \\
\hline$\cdot, \wedge 0$ & $\varepsilon$ & $r V$ & 79 & $\cdot, \wedge 0$ & $r$ & rq & 19 \\
\hline$\bullet, v$. & 0 & Yz & v. & $\cdot, \wedge l$ & $r$ & ro & r. \\
\hline$\cdot, \wedge 0$ & $r$ & rq & $r_{1}$ & •,Al & 1 & rr & $r$ \\
\hline$\bullet, r \cdot$ & 10 & rr & Vr & $\cdot, r$. & $\wedge$ & rV & rr \\
\hline •, & 18 & ro & Vr & •, rV & Ir & rr & $r r$ \\
\hline r & $1 \xi$ & $r r$ & V乏 & •, & 10 & Tr & $Y \xi$ \\
\hline$\cdot, 10$ & $r$ & rq & vo & •, IV & $r$ & ro & ro \\
\hline$\cdot, \mathrm{\wedge}$ & 1 & $r r$ & vi & $\bullet, \S 1$ & 17 & rV & rq \\
\hline$\cdot, \wedge 1$ & 0 & $r V$ & Vr & •, & $1 \varepsilon$ & rq & $r V$ \\
\hline •, $\mathrm{s}$ & 0 & ro & $r \wedge$ & $\cdot, \mathrm{VA}$ & $r$ & Yz & rA \\
\hline$\cdot, \mathrm{v}$ & $\xi$ & $r \xi$ & Vq & $\cdot, \wedge 0$ & $r$ & rq & $\mathrm{rq}$ \\
\hline - Ir & $\varepsilon$ & $r r$ & $\Lambda^{\prime}$ & •,Al & 1 & rr & r. \\
\hline •, & ir & TE & $\Delta 1$ & r & 17 & ro & rI \\
\hline$\cdot, 19$ & $r$ & $r q$ & Ar & •,§l & 11 & rr & rr \\
\hline$\cdot, \wedge 9$ & $r$ & $r v$ & $\Delta r$ & •, & Ir & ro & rr \\
\hline •, Tr & $r$ & $r_{0}$ & $\Lambda \varepsilon$ & $\cdot, \mathrm{V}$ & 0 & ro & $\psi \varepsilon$ \\
\hline$\cdot, 10$ & $r$ & ro & 10 & •,Or & 1. & Yq & ro \\
\hline$\cdot, \mathrm{V}$ & $r$ & $r r$ & 19 & $\cdot, r \cdot$ & Ir & $r_{0}$ & $r q$ \\
\hline זוף, & 0 & rr & Av & $\cdot, 07$ & 0 & $r_{0}$ & $r v$ \\
\hline •, वr & 1 & $r q$ & $\wedge \wedge$ & •, rv & Ir & $r r$ & rA \\
\hline$\cdot, 97$ & • & $r q$ & 19 & $\cdot, r$. & $r$ & Mr & $r q$ \\
\hline$\cdot, \mathrm{VA}$ & 0 & $r q$ & 9. & $\cdot, 10$ & • & $r r$ & $\xi$ \\
\hline •, IV & $r$ & $r_{0}$ & 91 & $\bullet, r \cdot$ & 17 & Y乏 & $\$ 1$ \\
\hline$\cdot, r$. & $r$ & $M$ & ar & $\cdot, \mathrm{V \Sigma}$ & 0 & ro & $\xi Y$ \\
\hline$\bullet, v_{\bullet}$ & $\varepsilon$ & $r r$ & ar & •, rV & Ir & rr & $\varepsilon r$ \\
\hline$\cdot, \wedge 1$ & $\varepsilon$ & $r q$ & $9 \xi$ & $\cdot, 10$ & $r$ & ro & $\llbracket \xi$ \\
\hline$\cdot, \mathrm{VA}$ & 0 & $r q$ & 90 & $\cdot, r$. & $r$ & Mr & $\$ 0$ \\
\hline$\cdot, r v$ & $1 \varepsilon$ & TE & 97 & •,or & $r$ & MI & 57 \\
\hline$\cdot, \mathrm{VA}$ & • & $r I$ & $9 \mathrm{~V}$ & $\cdot, \wedge 0$ & $r$ & ro & $\{v$ \\
\hline$\cdot, v_{0}$ & 1 & $r_{0}$ & 91 & •, & 0 & $r r$ & $\$ 1$ \\
\hline$\cdot, \mathrm{VA}$ & 0 & $r q$ & 99 & $\cdot, \wedge 1$ & $r$ & TE & $\leqslant 9$ \\
\hline$\cdot, 07$ & 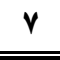 & $r r$ & 1.0 & $\cdot, 09$ & 0 & $r$ & 0. \\
\hline
\end{tabular}

حيث أن Q تشير إلى رقم السؤال، D تشير إلى عدد التلاميذ - من مجموعـة التلاميذ منخفضي التحصيل- الذين اجابوا اجابه صحيحة على المفردة، U تشير إلى عدد الطلاب-من 
مجموعة التلاميذ مرتفعى التحصيل- الذين اجابوا اجابه صحيحة على المفردة .كما يشير قيمة معامل التمييز ويوضتح جدول(^) قيم معاملات التمييز والتى تراوحت بين (. . .ب للمفردة رقم

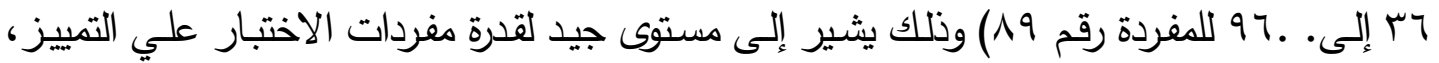

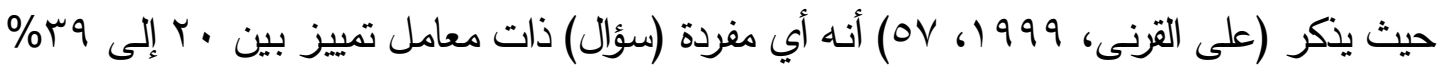
تعتبر ذات تمييز مقبول وأي مفردة ذات تمييز أعلى من وب\% تعتبر مفردة جيدة التمييز.

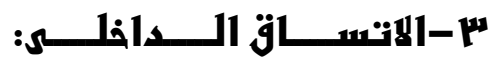

تـم حسـاب الاتسـاق الــاخلي للاختبارباسـتخدام برنــامج SPSS علـى عينـة الدراســة الاستطلاعية ( . . 1) تلميذ وتلميذة من خلال حساب قيمة معاملات الارتباط بين درجة كل مفردة والدرجة الكلية للاختبار بعد حذف درجة المفردة من درجة الاختبار ككل وجدول (ب) يوضح ذلك.

جلول (ץ) معاملات الارتباط بين درجة المفردة والدرجة الكلية للاختبار التحصيلى

\begin{tabular}{|c|c|c|c|c|c|c|c|}
\hline مـامعامل الارتباط & | & |معامل الارتباط & |السؤال & |معامل الارتباط & |السؤال & |معامل الارتباط & | السؤال \\
\hline$* *$, , $\wedge r \square$ & VID & $* * \bullet, 09 \varepsilon \square$ & 015 & 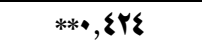 & 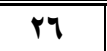 & ***,V•1し & 15 \\
\hline$* * \bullet, 7 \leqslant \wedge \square$ & $v v \square$ & $* * \bullet, 7 \leqslant 9 \square$ & or & **॰, r $\leqslant q \square$ & rVL & $* * \bullet, 0 \wedge 7 \square$ & $r$ \\
\hline$* * \bullet, 097 \square$ & VA & **•, ๆ ๆ ป & or & **•ๆYIL & YAL & **•,r r & $r \square$ \\
\hline$* * \bullet, Y \mid \varepsilon \square$ & $v q \square$ & $* * \bullet, \Delta V \cdot \square$ & 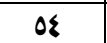 & $* * \bullet$, Y $Y V \square$ & rqL & $* *$, , $0 ૫ \square$ & $\varepsilon$ \\
\hline$* * \bullet, 01 \lambda \square$ & $\Lambda \cdot \square$ & 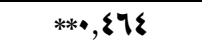 & $\Delta \Delta \square$ & **॰, ๆ ๆ ป & $r \cdot \square$ & $* * *,\{Y Y \square$ & $\Delta \square$ \\
\hline **•,rqr & 11 & $* * \bullet, \Delta 0 r \square$ & oy & **॰, r $\leqslant 1 \square$ & rIL & **•,รVV & $7 \square$ \\
\hline$* * \bullet, \neg \vee \neg \square$ & ArL & **^,OrV & ov & $* * \bullet, r \cdot r \square$ & rrL & $* * \bullet$, orA $\square$ & $\mathbf{v}$ \\
\hline$* * \bullet, \operatorname{IVY}$ & ArL & $* *, \Delta \Lambda \cdot \square$ & 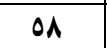 & $* * \cdot \xi \cdot \varepsilon \square$ & rrL & $* * \bullet, \$ 00 \square$ & $\Lambda \bigsqcup$ \\
\hline$* * \bullet, 0 \leqslant 9 \square$ & A $\varepsilon \square$ & **•, OIYL & $\Delta 9 L$ & $* *, 07 \cdot \square$ & rदा & $* * \bullet, r \Lambda \cdot \square$ & $9 \square$ \\
\hline$* * \bullet, V \cdot V \square$ & १०८ & **•,VYI & $7 \cdot \square$ & 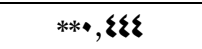 & roL & $* * \bullet, \xi \bullet \bullet \square$ & $1 \cdot \square$ \\
\hline$* *, 07 \Lambda \square$ & Aฯ & $* * \bullet, 017 \square$ & 71 & $* \bullet, r \cdot \varepsilon \square$ & rqL & 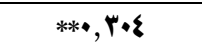 & 11 \\
\hline$* * \bullet, 0 . \wedge \square$ & Av & $* *, 07 r \square$ & 7rL & $* * \bullet, § 00 \square$ & rvL & $* * \cdot, 0.9 \square$ & IrL \\
\hline$* * \bullet, V r \cdot \square$ & $\wedge \wedge \square$ & **•, ๆrq & $7 r \square$ & $* * \bullet$, rar & rA & 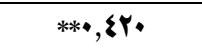 & irL \\
\hline$* * \bullet, Y Y \neg \square$ & 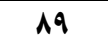 & $* * \bullet, 79 \Lambda \square$ & $7 \varepsilon \square$ & **•, OrA $\square$ & $r q \square$ & $* * \bullet, 001 \square$ & $1 \varepsilon$ \\
\hline$* * \bullet, 091 \square$ & $9 \cdot \square$ & $* *,\{77 \square$ & $70 \square$ & $* * \bullet$, VOV $\square$ & $\xi \cdot \square$ & $* * \bullet$, IrrL & $10 \square$ \\
\hline$* *, 0 \leqslant \Lambda \square$ & $91 \square$ & ***,orV & $77 \square$ & $* * \bullet$, rq० & «ाए & $* * \bullet, 091 \square$ & $17 \sqcup$ \\
\hline$* * \bullet, 0 \wedge \varepsilon \square$ & art & $* *, Y \backslash V \square$ & 7V & $* * \bullet, \Delta 0 \mathrm{~V} \square$ & $\varepsilon r \square$ & $* * \bullet, 010 \square$ & IVL \\
\hline **•,ovrL & art & $* *$ *IVY & $71 \square$ & $* *$, rar & srप & 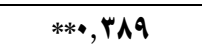 & $M \square$ \\
\hline$* *, 701 \square$ & $9 \varepsilon \square$ & $* * \bullet, V \cdot r \square$ & $79 \square$ & $* * \bullet$, IVY & «६ए & $* * \bullet, ~ \backslash \leqslant 0 \square$ & $19 \square$ \\
\hline **•, II\& & $90 \square$ & 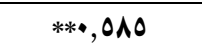 & $r \cdot \square$ & ***,orl & ६० & $* * \bullet, 0 \wedge \Lambda \square$ & $r \cdot \square$ \\
\hline **•, YY\& & $97 \square$ & **•, , YOY & vL & $* * \bullet,\{\cdot \xi \sqcup$ & รุป & $* * \bullet, 7 \leqslant 1 \square$ & rIL \\
\hline$* * \bullet, Y \cdot V \square$ & $9 v \square$ & $* * \bullet, Y \wedge \Lambda \square$ & VYL & $* * \bullet, 097 \square$ & §V & $* *, 0 \wedge \neg \square$ & rrL \\
\hline$* * \bullet, 0 \leqslant V \square$ & $9 \Lambda \square$ & **•, rrrL & $v r L$ & $* * \bullet,\{70 \square$ & $\xi \wedge$ & **•, YqY & $r r L$ \\
\hline$* * \bullet$, IrV & $99 \square$ & **॰, Y৭\& & Vह & $* *, 090 \square$ & $\{9 \square$ & $* * \bullet, r \vee \Lambda \square$ & rEL \\
\hline$* * \bullet$, ¿qr & $1 . \cdot \square$ & $* *, 700 \square$ & voL & $* *,\{\wedge 0 \square$ & $0 . \square$ & $* * \bullet,\{90 \square$ & roL \\
\hline
\end{tabular}


يتضـح مـن جدول (9) أن قيم معـاملات الإرتبـاط جميعها دالـة إحصـائياً عند مستوى

(1 ( . • ) مما يؤكد علي الاتساق الداخلى للاختبار التحصيلى الموضوعى.

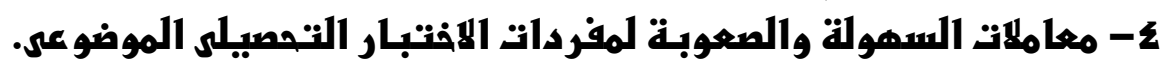

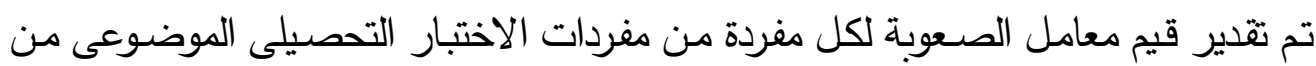

خلال قسمة عدد الذين أجابوا إجابة صحيحة علي المفردة على العدد الكلي للذين اجابوا على المفردة

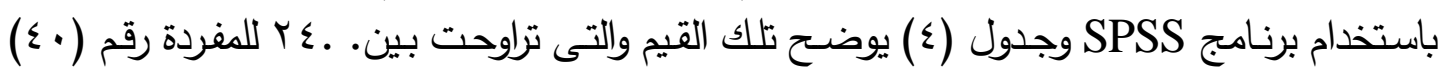

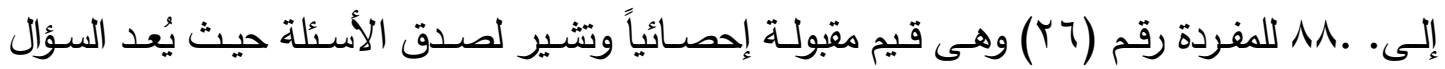
(المفردة) مقبولا إذا تراوحت قيمة معامل الصعوبة له بين (10 , . -. .10 )، كون المفردة التي يقل

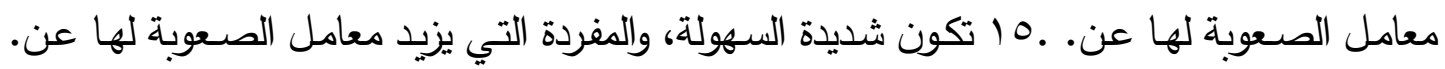

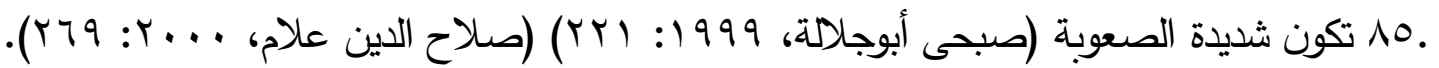

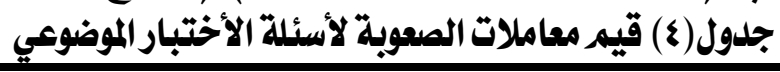

\begin{tabular}{|c|c|c|c|c|c|c|c|}
\hline قآلصيم معاملات & |السؤال & "آيهم معاملات & ـالسؤال & "قآلصعوبة معاملات & |السؤال & "آلصعموبة معاملات & السؤال \\
\hline$\cdot, Y \wedge \square$ & vy & •,\&YL & $01 \square$ & $\cdot, \wedge \wedge \square$ & rYL & •, $\vee v \square$ & $1 \square$ \\
\hline$\cdot, 0$ & $v v \square$ & $\cdot, \& Y \square$ & or & $\cdot, 7 \xi \square$ & $r v \square$ & $\cdot, 07 \square$ & $r$ \\
\hline$\cdot, \boldsymbol{\imath} \mathbf{r} \square$ & VA $\square$ & $\bullet, 07 \square$ & or $\square$ & $\bullet, 79 \square$ & rA & $\cdot, \mathrm{VOL}$ & $r$ \\
\hline - roL & $v a \square$ & $\cdot, \leqslant 0 \square$ & $0\}$ & $\cdot, V \cdot \square$ & $r q L$ & $\cdot, \vee \vee \square$ & $\varepsilon$ \\
\hline$\cdot, 01 \square$ & $\Lambda \cdot \square$ & $\cdot, \gtrless 0 \square$ & $\Delta \Delta \sqcup$ & $\cdot r \cdot \square$ & $r \cdot \square$ & $\cdot, 7 \Lambda \sqcup$ & $\Delta \square$ \\
\hline$\cdot, 7 r \square$ & AIL & $\cdot, 09 \square$ & $07 \square$ & $\cdot, \wedge \varepsilon \square$ & mL & $\cdot, \mathrm{VI}$ & $7 \mathrm{TL}$ \\
\hline$\cdot, \leqslant 7 \square$ & ArL & •, ov $\square$ & ov! & $\cdot$, ov $\square$ & rrL & $\cdot, \vee \neg \square$ & $v \square$ \\
\hline •, or $\square$ & ArL & $\cdot,\{v \square$ & $\Delta \wedge \square$ & $\cdot, r \cdot \square$ & 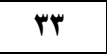 & $\cdot, 0 \wedge \square$ & $\mathbf{A} \square$ \\
\hline •,rrL & A $\varepsilon \square$ & $\cdot, 0 \cdot \square$ & $\Delta 9 \square$ & $\cdot, 7 r L$ & rह & $\bullet, 71 \sqcup$ & $9 \square$ \\
\hline$\bullet, \leqslant 7 \square$ & 10! & $\cdot$, ov $\square$ & $7 . \square$ & $\cdot, 7 r \square$ & roL & $\cdot, 70 \square$ & $1 . \square$ \\
\hline$\cdot, \S 0 \square$ & งๆ & $\cdot, \llbracket \llbracket \square$ & 71 & $\cdot, 09 \square$ & rqL & $\cdot, 7 r L$ & $11 \mathrm{~L}$ \\
\hline$\cdot, \boldsymbol{\imath r} \square$ & $\mathbf{A v} \square$ & $\cdot$, roL & 7rL & $\cdot, 09 \square$ & $r v \square$ & $\cdot, 7 r \Delta$ & IrL \\
\hline$\cdot, \$ 0 \square$ & $\wedge \wedge$ & $\cdot, 00 \square$ & $7 r$ & $\cdot, 00 \square$ & ra & $\cdot, \wedge \cdot \square$ & IrL \\
\hline$\cdot, \S 0 \square$ & 19 & $\cdot, 09 \square$ & $7 \varepsilon \square$ & $\cdot, § 0 \square$ & $r q \square$ & $\cdot$, ov $\square$ & $1 \varepsilon$ \\
\hline$\cdot, 01 \square$ & $9 \cdot \square$ & •, Or & $70 \square$ & $\cdot, r \varepsilon \square$ & $\varepsilon \cdot \square$ & $\cdot, 7 r L$ & $10 \square$ \\
\hline$\cdot, r v \square$ & $91 \square$ & $\cdot,\{v \square$ & $97 \square$ & $\cdot, 79 \square$ & \&1 & $\cdot, 70 \square$ & $17 \square$ \\
\hline$\bullet, r \xi \square$ & art & $\bullet, \S 1 \square$ & 7VL & $\bullet, 0 \wedge \square$ & \&YL & $\bullet, 71 \bigsqcup$ & IV \\
\hline$\cdot, r v \square$ & art & $\bullet, \neg \Lambda \square$ & $71 \square$ & $\cdot, 7 \cdot \square$ & $\varepsilon r \square$ & $\cdot, 09 \square$ & $1 \mathrm{~A} \square$ \\
\hline$\cdot, \xi \cdot \square$ & $9 \varepsilon$ & $\cdot, \leqslant 7 \square$ & $79 \square$ & $\cdot, 81 \square$ & sईए & $\cdot, 7 \varepsilon \square$ & $19 \square$ \\
\hline$\cdot,\{\wedge \square$ & $90 \mathrm{~L}$ & $\cdot,\{9 \square$ & $v \cdot \square$ & $\cdot,\{9 \square$ & soL & $\cdot, 70 \square$ & $r \cdot \square$ \\
\hline$\cdot, 01 \square$ & $97 \square$ & $\bullet, \leqslant 7 \square$ & vi & •,orL & $\varepsilon 7 \square$ & $\cdot, \xi \cdot \square$ & ML \\
\hline •,rrL & 9r & $\cdot, 0 \Lambda \square$ & rrL & •, or $\square$ & sv & $\cdot, \mathrm{V} \leqslant \square$ & rYL \\
\hline$\cdot, r \cdot \square$ & $9 \Lambda \square$ & $\cdot, 09 \square$ & vrL & $\cdot, \S 0 \square$ & $\xi \wedge \square$ & $\cdot, 7 \wedge \square$ & 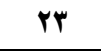 \\
\hline$\cdot, 0\} \square$ & $99 \square$ & $\cdot, 7 Y$ & $v \varepsilon$ & •,OYL & $\varepsilon q$ & $\bullet, 7 \Lambda \square$ & rk \\
\hline$\cdot, \S 0 \square$ & $1 \cdots \square$ & $\cdot,\{\wedge \square$ & rol & $\cdot, \xi \cdot \square$ & $0 . \square$ & $\bullet, 0 \wedge \square$ & ro \\
\hline
\end{tabular}




\section{ثبات الافتبار التهصيلى الموضو عي "التعلقة على البدول".}

قامت الباحثة بحساب ثبات الاختبار باستخدام برنامج SPSS حيث كالئ كانت قيمة معامل

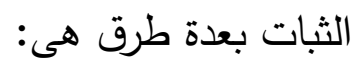

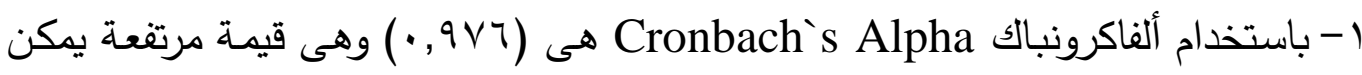

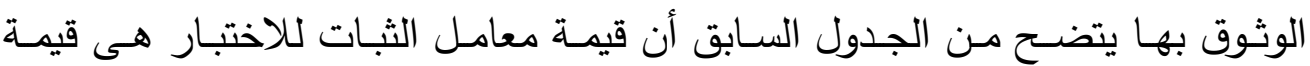

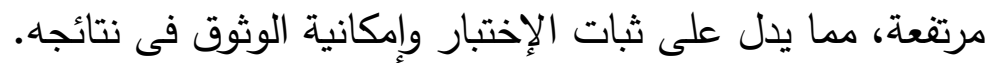

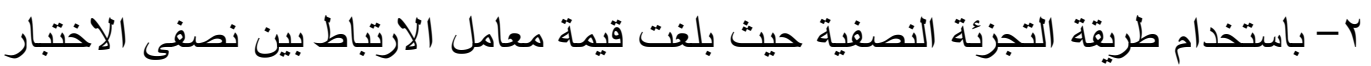

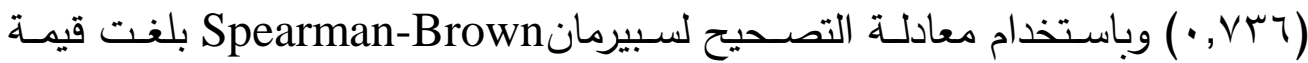

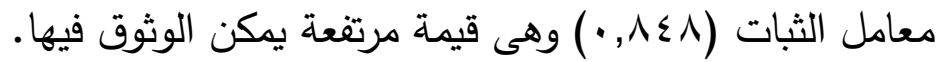
الاتساق الدافلي (ثبات الهفردات)

قامت الباحثة بحساب معامل الارتباط بين (درجة كل مفردة والدرجة الكلية للاختبار )

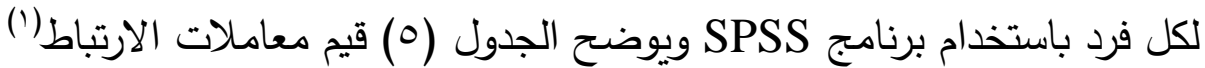

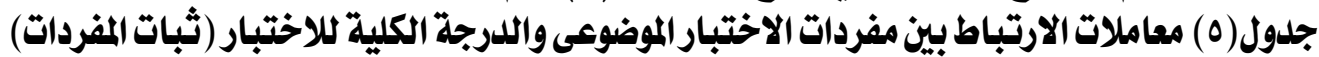

\begin{tabular}{|c|c|c|c|c|c|c|c|}
\hline |[ـ|معامل الارتباط & |كالسؤال & لــــعامل الارتباط & | السؤال & لــــعامل الارتباط & |كالسؤال & لــ[معامل الارتباط & |السؤال \\
\hline **•, १9)】 & Vq & 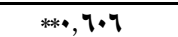 & $01 \square$ & ***,\{ro】 & rqL & $* * *, v \cdot q \square$ & 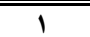 \\
\hline$* * \bullet, 709 \square$ & Vv & **•, 7ฯ•レ & orL & 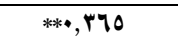 & TYL & $* * \bullet, 09 \Lambda \square$ & $r$ \\
\hline$* * \bullet, \eta+\wedge \square$ & VA $\square$ & 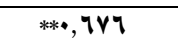 & ort & $* *$, , IrrL & rA $\square$ & ***, rov $\square$ & $r \square$ \\
\hline **•, Ir】 & va $\square$ & $* * \bullet$, OArL & oई! & $* * *$, IV\ & $r q \square$ & $* * \bullet,\{79 \square$ & $\varepsilon$ \\
\hline **•, OrY & $\lambda \cdot \square$ & $* * \bullet,\{\vee \wedge \square$ & $\Delta 0 \square$ & 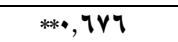 & $r \cdot \square$ & $* * \bullet,\{\xi \mid \square$ & $0 \square$ \\
\hline$* * \bullet, r V A \square$ & এ॥ & $* * \bullet, 077 \square$ & $07 \square$ & ***, ror $\square$ & mL & $* * \bullet,\{q \mid \square$ & $7 \square$ \\
\hline **•, १^】乙 & ArL & $* * \bullet, 00 \cdot \square$ & ov $\square$ & $* * \bullet, r, \square \cdot \square$ & rYL & $* * \bullet, 0 \xi \cdot \square$ & $v \square$ \\
\hline$* * *$, YAYL & ArL & $* * \bullet, \Delta 9 r \square$ & OAL & ***,\&|व & rrL & $* * \bullet,\{v \cdot \square$ & $\Delta \square$ \\
\hline ***, 071 & Aईए & **•,orq & $09 \square$ & ***,orr【 & r६६ & $* * \bullet$, raq & $9 \square$ \\
\hline 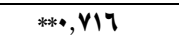 & 10ए & $* * \bullet, Y r \cdot \square$ & $7 . \square$ & 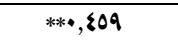 & roL & $* * \cdot\{r \mid \square$ & $1 \cdot \square$ \\
\hline ***, OAI & 19प & $* * \bullet$, Or. $\square$ & $71 \square$ & *•,YYYL & rqL & $* * \bullet, \S 19 \square$ & $11 \square$ \\
\hline **•, orr & 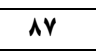 & $* * \bullet$, ovo $\square$ & 7rL & $* * \bullet, \xi V \cdot \square$ & $r v \square$ & $* * \bullet$, orr $\square$ & IrL \\
\hline **•, VYA & AM $\square$ & $* * \bullet, 7 \leqslant \wedge \square$ & $7 r \square$ & $* *, r M \square$ & ra $\square$ & ***,\&FY & irL \\
\hline **•,Yro & 19! & $* * *, V \cdot \wedge \square$ & 7हए & $* * \bullet, 0 \leqslant Y \square$ & $r q \square$ & 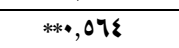 & $1 \varepsilon$ \\
\hline$* * \bullet, 71 \cdot \square$ & $9 . \sqcup$ & $* * \bullet,\{\wedge \mid \square$ & $70 \square$ & **•, Vท\& & $\xi \cdot \square$ & $* * \bullet, 7 \leqslant r \square$ & $10 \square$ \\
\hline$* * \bullet, 071 \square$ & $91 \square$ & $* * \bullet, 0 \leqslant \cdot \square$ & $97 \square$ & $*_{* * \bullet, r M \square}$ & छाए & $* * \bullet, 7 \cdot r \square$ & 17 \\
\hline 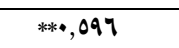 & $9 r \square$ & 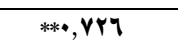 & TVL & $* * \bullet, \Delta v \cdot \square$ & \&YL & $* * \bullet$ OYA $\square$ & IVL \\
\hline 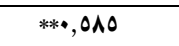 & $9 r \square$ & 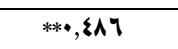 & $71 \square$ & $* * \cdot, r \mid \cdot \square$ & \&rL & $* * \bullet,\{\cdot 0 \square$ & IA \\
\hline 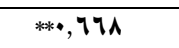 & १६ธ & ***,YIrড & $79 \square$ & **•, $7 \wedge \uparrow \square$ & «६! & **•, 707 & $19 \square$ \\
\hline **•, ๆr】 & $90 \square$ & $* * \bullet, 091 \square$ & $v \cdot \square$ & $* * \bullet, 0 \leqslant 0 \square$ & ร०\ & $* * \bullet, 099 \square$ & $r \cdot \square$ \\
\hline$* * \bullet, \forall \xi \mid \square$ & 99 & **•, ᄀฯ & $\begin{array}{lll} \\
1\end{array}$ & $* * \bullet,\{r \cdot \square$ & ६१ए & **•, yorL & rIL \\
\hline ***, 71A & $9 Y \square$ & $* * \bullet, r \cdot 0 \square$ & VYL & $* * \bullet, \nearrow \cdot \wedge \square$ & \{vए & 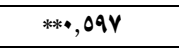 & rYL \\
\hline$* * \bullet, 009 \square$ & $9 \Lambda \square$ & $* *$, , ro. $\square$ & vr & $* * \bullet,\{\Lambda \cdot \square$ & «॥ $\square$ & ***,rir] & rro \\
\hline ***, १ 7 ra & $99 \square$ & ***, rाI & v\&! & $* * *, 7 \cdot \wedge \square$ & $\leqslant 9 \square$ & ***, ra\& & T\& \\
\hline$* * \bullet, 0.7$ & $1 . . \square$ & $* * \bullet, 770$ & vo & $* * \bullet,\{99 \square$ & $0 . \square$ & $* * \cdot, 0.9 \square$ & ro \\
\hline
\end{tabular}

(1) تعبر عن قيم جميعها دالـة أحصـائيا عن وجدود اتسـاق داخلى بين درجات الطـلاب على كل مفردة والمجموع الكلى لدرجات الطلاب على نفس المفردات. 


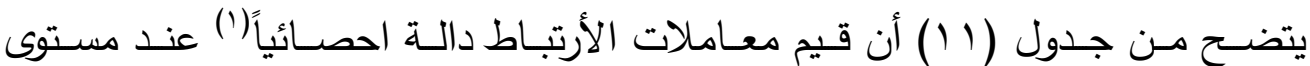

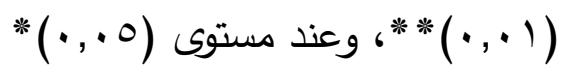

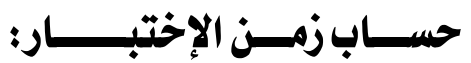

تم تحديد الزمن اللازم لتطبيق الاختبار التحصيلى، عن طريق حساب المنوال، فتم حساب منوال الأزمنة التى استغرقتها كل تلميذة من تلميذات العينة الاستطلاعية فى الإجابة عن مفردات

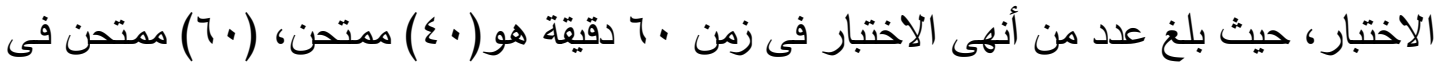
زمن • 9 دقيقة، بناءً على ذلك فان الزمن اللازم للإجابة عن مفردات الاختبار هو( • 9) دقيقة.

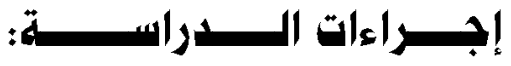

$$
\text { سارت إجراءات الدراسة الحالية على النحوالتالى: }
$$

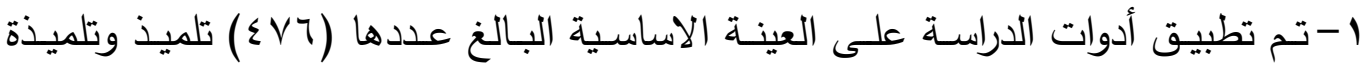

بالصف الثانى الأعدادى.

ץ-تم تصحيح أداة الدراسة وإعداد ملف البيانات بهدف معالجتها إحصائياً.

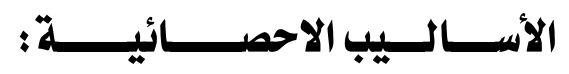

تم استخدام البرنامج الإحصائى "WINSTEPS"بهدف استبعاد الأفراد والمفردات غير الملائكـة إحصـائياً لأسس القيـاس الموضـوعى وأيضـاً تـدريج المفردات، وتقدير قدرات الأفراد المقابلة لكل درجة خام احتمالية وإيجاد قيمة دالة المعلومات لكل اختبار •

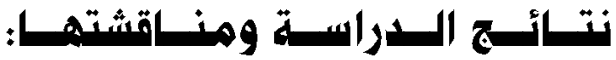

يُعرض فيما يلى نتائج الدراسة ومناقشتها:

نتائج فرض الاراسـة: ينص الفرض على أنسه "تختلف تقديرات معلم صعوبة المفردة

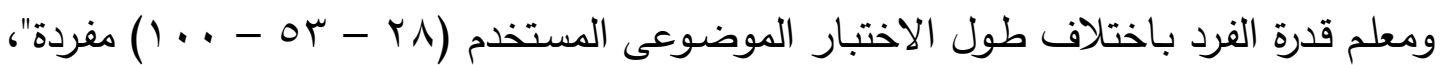
وللتحقق من صـحة الفرض الرابع: استخدمت الباحثة نموذج راش لتحليل البيانات من خـلال البرنامج الإحصائى (Winsteps) لتدريج مفردات الاختبار الموضوعي باختلاف طول الاختبار

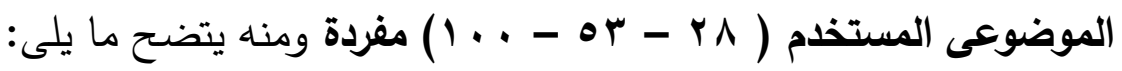

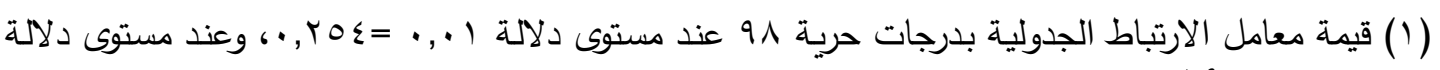
$\cdot, 190=\cdot, 0$ 
أولاً : بالنسبة لتحليل الاختبار الموضوعى باستخلاه اختبار طوله ( (1 مفردة) .

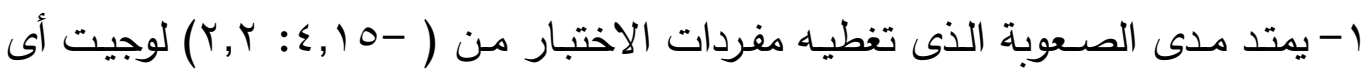

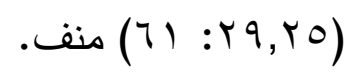

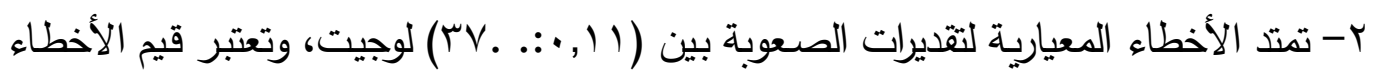

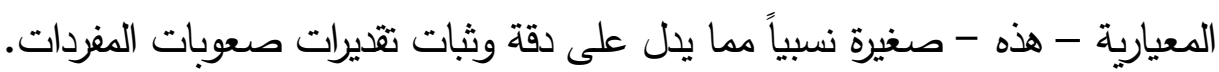

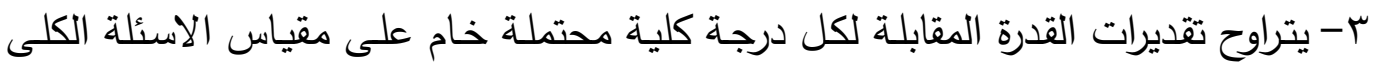

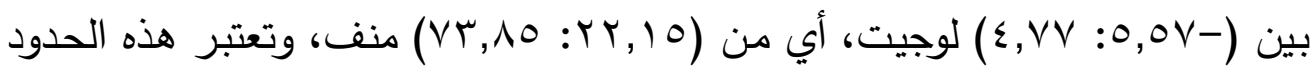
أقصى حدود للقدرة يمكن تقديرها.

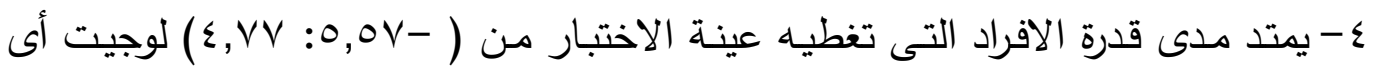

$$
\text { منف (VT, No: Y Y, 10) }
$$

0- مقدار المعلومـات الذى يعطيها الاختبار الموضوعى القصير عند مستوى قدرة (ق)

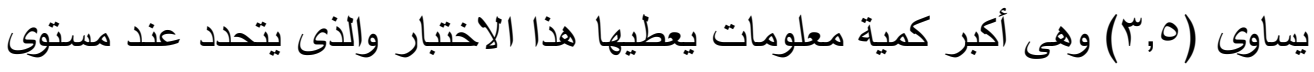

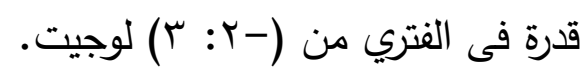

ويمكن حسـاب قيمـة الخطأ المعيـاري لهـذا الاختبـار باستخدام المعادلـة التاليـة: وتعد تلك القيمة للخطأ المعيارى أقل مايمكن $\operatorname{S.E}(\theta)=\frac{1}{\sqrt{I(\theta)}}=\frac{1}{1.9}=0.53$

$$
\text { عند نفس الفترة من (-r:r) (r). }
$$

\section{ثانياً: بالنسبة لتحليل الاختبار الموضوعى باستخداه اختبار طوله ( به مفردة) .}

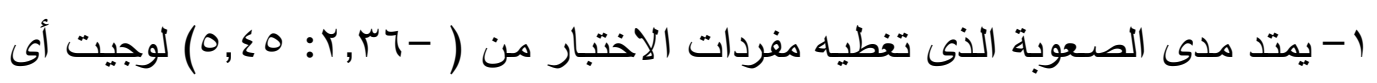

$$
\text { منف ( } \vee \vee, Y O: r \Lambda, r)
$$

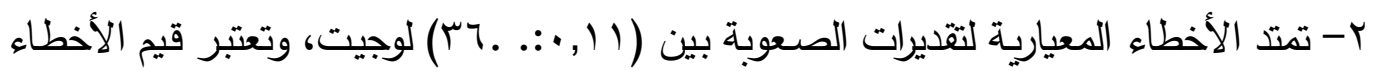
المعيارية - هذه - صغيرة نسبياً مما يدل على دقة وثبات تثديرات صعوبات المفردات.

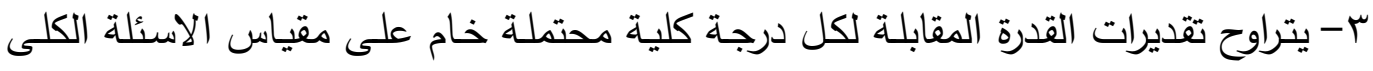

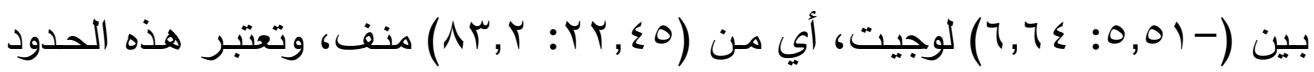

$$
\text { أقصى حدود للقدرة يمكن تقديرها. }
$$

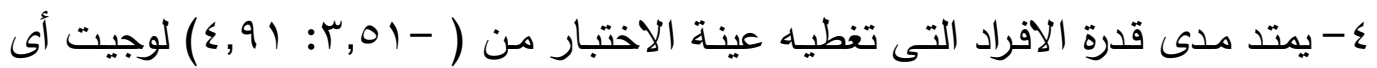

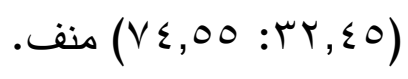


0- مقدار المعلومات الذى يعطيها الاختبار الموضوعى متوسط الطول عند مستوى قدرة

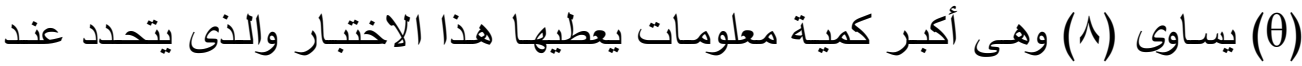

$$
\text { مستوى قدرة فى الفتري من (-) r: r) لوجيت. }
$$

" ويمكن حسـاب قيمـة الخطـأ المعيـاري لهـا الاختبـار باسـتخدام المعادلـة التاليـة:

وتعد تلك القيمة للخطأ المعيارى أقل مايمكن $\mathrm{S.E}(\theta)=\frac{1}{\sqrt{\mathrm{I}(\theta)}}=\frac{1}{2.8}=0.35$

$$
\text { عند نفس الفترة من (-1: (Y). }
$$

\section{ثالثاً : بالنسبة لتحليل الاختبار الموضوعى باستخداه اختبار طوله ( •. امفردة).}

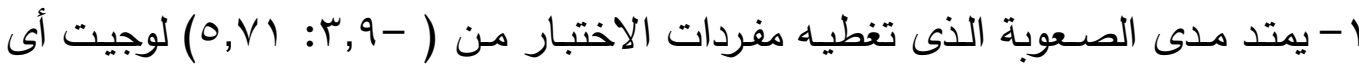

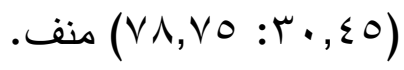

ץ- تمتد الأخطاء المعيارية لتقديرات الصعوبة بين (ץ ا , •.. ـ9ץ) لوجيت، وتعتبر قيم الأخطاء المعيارية - هذه - صغيرة نسبياً مما يدل على دقة وثبات تقديرات صعوبات المفردات. ب- يتراوح تقديرات القدرة المقابلة لكل درجة كلية محتملة خام على مقياس الاسئلة الكلى

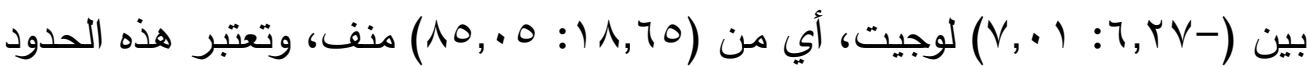
أقصى حدود للقدرة يمكن تقديرها باستخدام الاختبار الموضوعى.

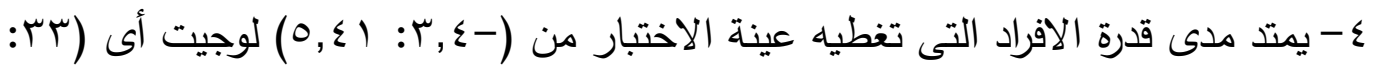

$$
\text { . SV, . } 0
$$

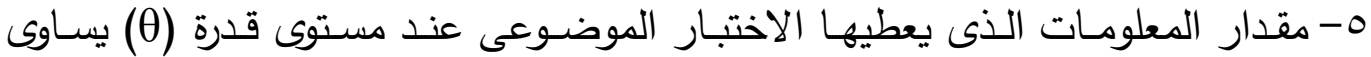
( ) ( ) وهى أكبر كمية معلومات يعطيها هذا الاختبار والذى يتحدد عند مستوى قدرة

$$
\text { فى الفتري من (- (: 1) لوجيت. }
$$

ويمكن حسـاب قيمـة الخطـأ المعيـاري لهذا الاختبـار باسـتخدام المعادلـة التاليـة: وتعد تلك القيمة للخطأ المعيارى أقل مايمكن $\mathrm{S.E}(\theta)=\frac{1}{\sqrt{\mathrm{I}(\theta)}}=\frac{1}{3.8}=0.26$ عند نفس الفترة من (-1: (1). 


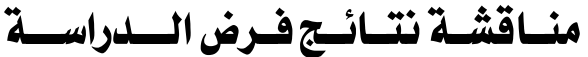

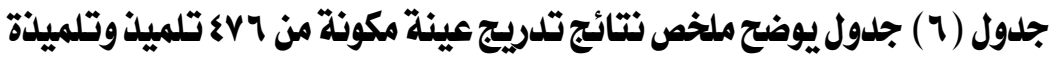

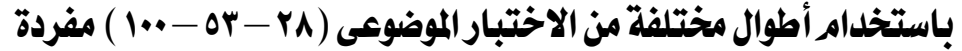

\begin{tabular}{|c|c|c|c|c|c|c|}
\hline الخطأ المعيارى & دالآة معلومات & لكل القدرة المقلابلة & ملى قدرة الافراد & صلمعيارية لتقديرات الاخطاء & المفردات المكونه & الموضوعى المستخلدم الاختبار \\
\hline •, Or & $r, 0$ & $V r, \wedge 0: Y r, 10$ & $\mathrm{VY}, \wedge 0: Y r, 10$ & rv. .:•, II & $71:$ rq, ro & اختبار قصير مفردة) \\
\hline$\cdot$, ro & $\wedge$ & $A r, Y: Y Y, \& O$ & $V \S, \Delta 0: r r, \S 0$ & rq...:, & VV, ro: : rA, r & ( اخه مفردةر متوسط \\
\hline •, ז7 & $1 \xi, 0$ & $10,00: 11,70$ & $r v, \cdot 0: r r$ & rq. .:•, Ir & $V A, Y O: r \cdot, \Sigma \Delta$ & (.. اختبار طفودة) \\
\hline
\end{tabular}

بالنظر إلى جدول (7) يتضـح اختلاف تقديرات معلم صعوبة المفردة ومعلم قدرة الفرد ودالة

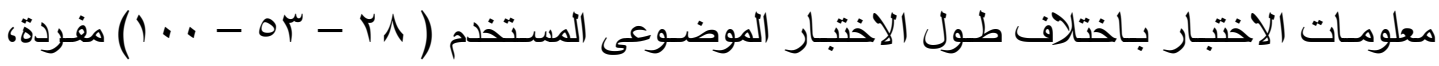

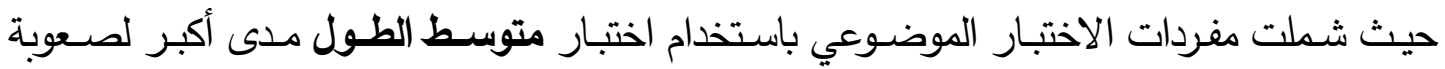

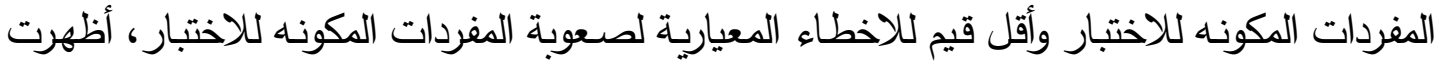
مفردات الاختبار الموضوعي باستخدام اختبار قصير أعلى مدى لقدرة الاقراد التى يقيسها الاختبار ، بينما أظهرت مفردات الاختبار الموضوعي باستخدام اختبار طويل مدى أعلى لتقديرات القدرة المقابلة

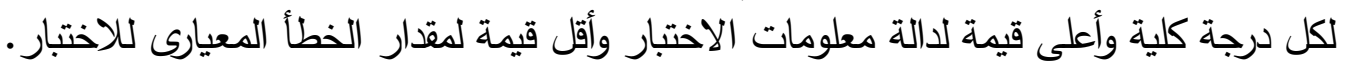

\section{علاقة نتيجة الفرض بنتائج الدراسات السابقة}

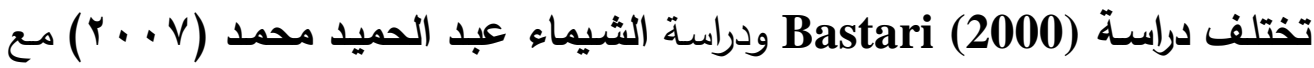

نتيجة الفرض الرابع فى أنه بزيادة طول الاختبار يزداد دقة بارامترات المفردة المكونه للاختبار . وتتفق مع دراسة (Sahin, A. \& Weiss, D., 2015) والتى تشير إلى أن زيادة طول بنك المفردة يحدث تأثير إيجابي على تقديرات قدرة الأفراد، كما أن المزيد من المفردات في

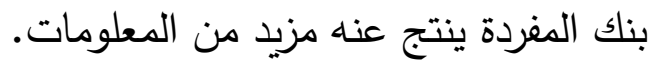

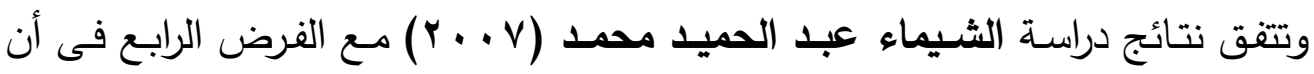
أفضل مطابقة للمفردات مع نموذج راش تتحقق عند الاختبار متوسط الطول. التوصيات المقترحة: يمكن الخروج بالتوصيات التالية بناء على نتائج الدراسة الحالية:

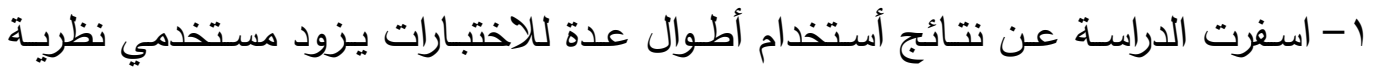
الاستجابة للمفردة بتوضيح تفصيلي حول أطوال للاختبار من أجل أستفادة مثلى من عن فئن عملية القياس. r- توصسى الباحثة فى ضـوء نتائج البحث الحسالى باستحدام اختبارات طويلـة ممـا يحقق خصائص سيكومترية أدق. 


\section{المســاجــــ}

\section{أولاً : المــراجــع العــربيـــة :}

1- أحمـد إسـماعيل الكحـلاوى، هنـد عبد المجيد الحمـورى (991 ( ). أسـتراتجيات بنـاء بنـك

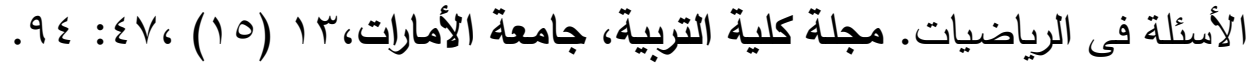
r- اعتدال غازى عبدالله ( . . . ( . القياس محكى المرجع لأحد مقررات علم النفس التعليمى، رسالة ماجستير غير منشورة، كلية التربية للبنات، جامعة عين شمس. ب- الثيماء عبد الحميد محمد (V. . . r). أثر كل من حجم العينة وطول الاختبار على دقـة نتاج الاختبارات التحصيلية مرجعية المحك فى الرياضيات باستخدام نموذج راش، رسـالة ماجستير غير منشورة • كلية التربية، جامعة الزقازيق. ع - أمين على محمد سليمان، رجاء محمود أبوعلام (9 . . ؟). القياس والتقويم فحى العلوم الإنسانية أسسة وأدواته وتطبيقاته . القاهرة: دار الكتاب الحديث. ه- أمينـة محمــ كـاظم, أنـور محمــ الشـرقاوى, سـليمان الخضـرى الثـيخ وناديةعيـــ السـلام (797 (19).اتجاهـات معاصـرة فـى القيـاس والتقـويم النفسـى والتربـوى. القـاهرة: مكتبـة الانجلو المصرية. 7- خالد بن حسن شيبان التميمى (999 (99). أثر كل من نوع المحكم وطول الاختبار على تحديد درجة القطع لاختبار محكى المرجع يقيس الكفايات الرياضية فى العمليات الحسابية على الأعداد بالصفف السـادس الابتدائى بمدينـة جدة، بحث مكمل لمتطلبـات نيـل درجـة الماجستير • كلية التربية. جامعة أم القرى. V- رضا سمير عوض (ع . . ץ). دراسة أثر عدد المفردات وموقع المفردة من الاختبار وحجم العينـة وعدد البدائل على قيمة معامل ثبات القياس، رسـالة ماجستير غير منشورة، معهد الدراسات التربويـة، جامعة القاهرة. ^- صلاح أحمد مراد، أمين على سليمان (0 . . ץ). الاختبارات والمقاييس فحى العلوم النفسية والتربوية خطوات إعدادها وخصائصها. طب . القاهرة: دار الكتاب الحديث.

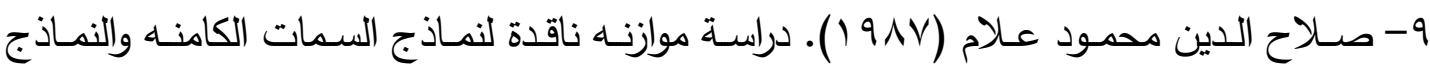

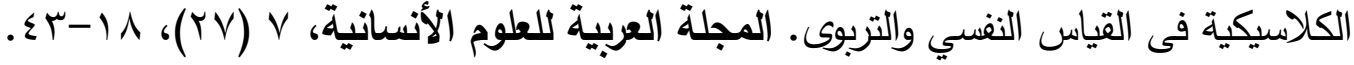




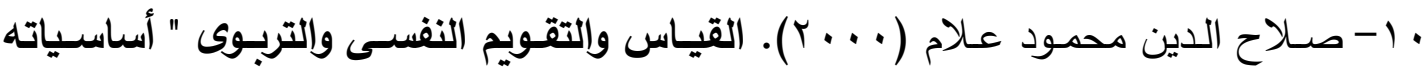
وتطبيقاته وتوجهاته المعاصرة". القاهرة: دار الفكر العربى.

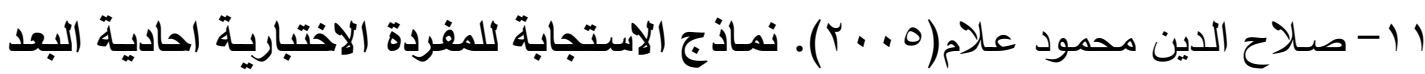
ومتعددة الابعاد وتطبيقاتها فى القياس النفسى والتربوى ـ القاهرة: دار الفكرالعربى.

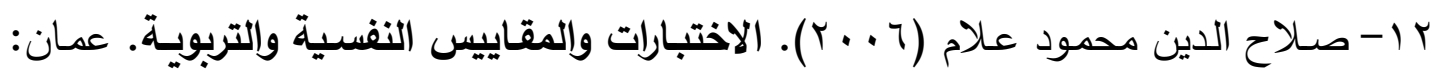

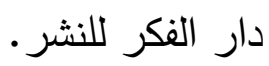

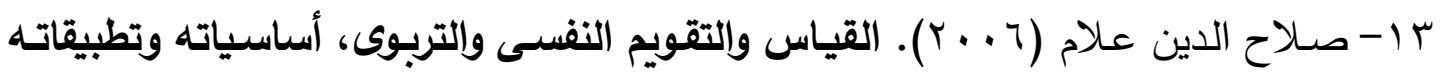
وتوجهاته المعاصرة. القاهرة: دار الفكر العربى.

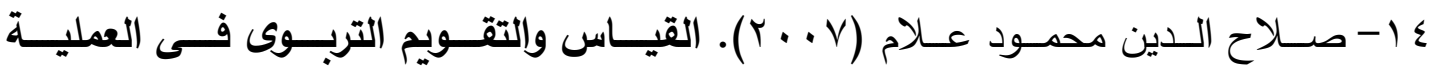
التدريسية.عمان: دار المسيرة.

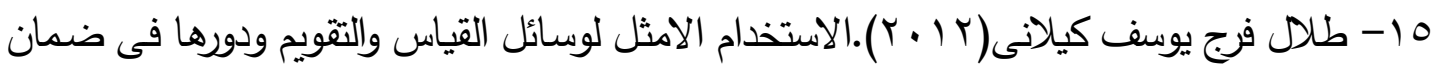

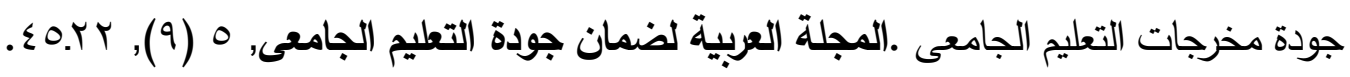
17 - محمد إبراهيم محمد محمد (· ( • ( ). استخدام نموذج التقدير الجزئى لتحليل مستويات بنية ناتج التعلم والاختبارات العنقودية ذات الفقرات المرتبة هرمياً لدى عينة من طلاب كلية التربية بالمنيا. رسالة دكتوراة غير منشورة , كلية التربية, جامعة المنيا. IV على تدريج بنود بنك الأسئلة. رسالة دكتوراة غير منشورة، كلية التربية، جامعة المنصورة.

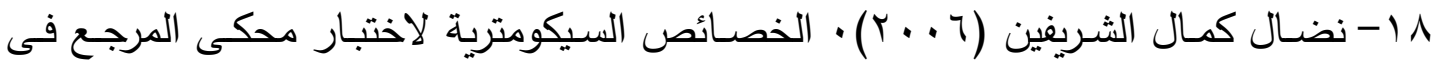
القياس والتقويم التربوى وفق النظرية الحديثة فى القياس التربوى والنفسى ـ مجلة العلوم

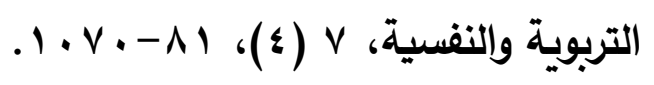

9 1- هثام فتحى محمد جاد الرب (999 (1). تطوير اختبار للذكاء باستخدام نماذج السمات الكامنه وأثر ذلك على قدرة الاختبار على التتبؤ بالتحصيل الدراسى، رسالة ماجيتير، جامعة المنصورة.

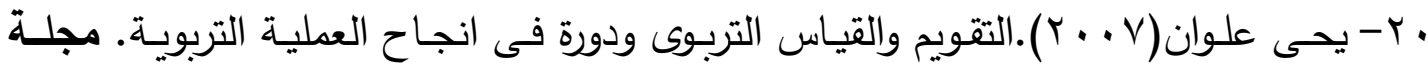

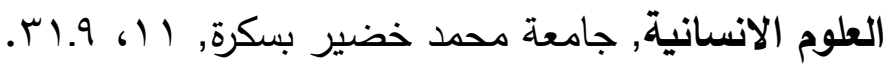




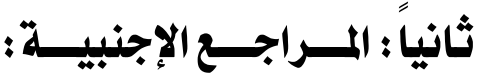

1- Abd.razak, n.\&khairani, a. and meethien, 1.(2012). Examining quality of mathematics test items using rasch model:preminarily analysis, available on line at http://www.science direct.com.

2- Akour, m. and Al-omari, h.(2013). Empricical investigation of the stability of irt item internationalon line journal of education sciences, vol.5, no.2, P.p .291-301 .

3- Baker, F.B. (2001).The Basics Of Item Response Theory. United States Of America.Port smouth, NH:Heinemann Educational Books.

4- Bastari, B. (2000). Linking multiple-choice and constructed-response items to a common proficiency scale.Submitted to the graduate school of the university of Massachusetts Amherst in partial fulfillment of the requirements for the degree of doctor of education.

5- Cunningham, G. (1986). Educational and Psychological Measurement. Macmillan Publishing Company New York, Collier Macmillan Publishers London.

6- Gleason, J.(2008).An Evaluation of Mathematics Competitions Using Item Response Theory . Notices Of The Ams , Vol.55, no.1, Pp.8-15.

7- Hidalgo, M. \& Martinez, M. \& Benito , J. and Guilera, G. (2016) . Acomparison of discriminant logistic regression and item response theory likelihood-Ratio tests for differential item functioning (IRTLRDIF) in polytomouse short tests, Psicothema. Vol.28, No.1, Pp.83-88.

8- Jiang, S.\&Wang, C. and Wess, D.(2016).Frontiers in psychology.Vol.7, February.

9- Kesamang, M.(2017).The comparison of item and person item response theory (IRT) parameter estimations for the anchor-items and common-persons designs, Herald Journal of educaton and general studies . Vol. 3, No. 1, Pp.1-12, March. 
10- Oji, E. \& Charles, I. (2016) . Transformation from classical test theory (CTT) to item response, URDO-Journal of education reseach . Vol.1, No.4, Pp.104:116.

11- Sahin, A. and Weiss, D. (2015).Effects of calibration sample size and item bank siz on ability estimation in computerized adaptive testing. Educational science theory \&Practice, December 2015, 15(6), 1585-1595.

12- Yousfi, S. (2012). Principles and Procedures of Considering Item Sequence effects in the development of calibrated item pools: conceptual analysis and empirical Mutation, psychological test and assessment Modeling, vol. 54, No. 4, Pp. 60- 396 